\title{
A Probabilistic Approach to Seismic Hazard in Metropolitan France
}

\author{
by Sylvie Marin, Jean-Philippe Avouac,* Marc Nicolas, and Antoine Schlupp
}

\begin{abstract}
In this study, we applied a probabilistic methodology to seismic hazard assessment in metropolitan France. For that purpose we determined an attenuation law adapted to the French context. This law holds for peak ground acceleration on stiff bedrock for earthquakes with local magnitudes between 2.5 and 5.6 recorded in near field (at distances between 3 and $50 \mathrm{~km}$ ). Geological conditions are taken into account by means of a three-categories classification of lithologies based on a $1 /$ 1,000,000 geological map. The seismotectonic zonation consists of areas of diffuse seismicity characterized by a frequency-magnitude distribution. In southeastern France, active faults are considered in a test case and are assumed to follow the characteristic earthquake model. We performed hazard curves for six French cities and maps of peak horizontal ground accelerations expected for return periods of 475 , 975, and 1975 years in the country. Sensitivity tests have been performed. The uncertainty introduced by ground-motion variability seems minor compared with that due to the choice of the attenuation law. This study points to the importance of testing internal consistency of the various data and laws used in any seismic hazard analysis (in particular, here the type of magnitude used to predict ground motion). If not, some systematic bias is introduced that may result in systematic errors on peak ground acceleration determination. We also show that the introduction of possibly very large and infrequent events, known only from paleoseismic investigations, may have a dramatic impact on the hazard, especially when long periods of time are considered.
\end{abstract}

\section{Introduction}

This article presents an application of probabilistic methods to seismic hazard assessment in France. This study differs from previous studies that have adopted a "deterministic" approach (Bour et al., 2000; Terrier et al., 2000). In both approaches it is assumed that seismicity can be represented from a seismotectonic model that consists of polygonal zones and faults with appropriate characteristics. This model is often referred to as "the seismotectonic zonation." In a deterministic approach, only one single scenario is used chosen from all its various possibilities, usually the most unfavorable. Each zone or fault is then characterized by a unique maximum plausible earthquake, which is assumed to have an evenly distributed spatial probability of occurrence. Once the reference scenario is chosen, and provided that attenuation laws and site effects are known, such an approach allows the estimatation of the (maximum) expected ground motions at any point. The resulting map is then very sensitive to any change in the geometry of the seismotectonic model or in the magnitude of the maximum plausible earthquakes, as well as to any reappraisal of site effects or

*Present address: Geological and Planetary Sciences, California Institute of Technology, Mail code 100-23, Pasadena, California 91125. attenuation laws. Moreover, uncertainties on the various parameters are usually incorporated by considering systematically the most conservative sets of parameters and fixed safety margins, yielding to probably unrealistic overestimations of hazard. Finally, the possibility that the ground motion may exceed the value obtained from a deterministic map can not be easily quantified. In view of these shortcomings, probabilistic methods have been designed (e.g., Cornell, 1968) and have become more and more popular. A probabilistic approach also requires a seismotectonic model, but the zones and faults are not characterized by a single maximum plausible earthquake. Polygonal zones are characterized by a frequency-magnitude distribution, generally assumed to fit the experimentally observed power-law distribution (Gutenberg and Richter, 1956). In general, faults are assumed to obey the characteristic fault model (Schwartz and Coppersmith, 1984), which, although debated, seems a reasonable assumption for seismic hazard assessment (Yeats et al., 1997). The main problem in applying probabilistic methods, in particular, in a low-seismicity area such as France, is that it requires a more elaborate description of the seismotectonic model, often poorly constrained from earthquake catalogs and seismotectonic studies. In another hand, 
the activity is not high enough and the seismic cycle not short enough, so that the observed seismicity could be used as an assumption representative of the seismic potential in zoneless methods. In the moderate but contrasted seismicity context of France, a zonation that integrates a more global knowledge about the seismotectonic model and its interpretation seems the best solution. In this study, we take advantage of the relatively good instrumental and historical seismicity catalogs (Laboratoire de Détection et de Géophysique [LDG], 1998; SIRENE, 1996). This study builds on a previous similar attempt by the Evaluation Probabiliste de l'Aléa Sismique (EPAS) group (EPAS, 1998a,b), from which it differs for two major reasons: (1) we have taken into account regional data to estimate the attenuation law and (2) we have incorporated some gross models to take geological conditions into account. At this point we have not fully accounted for uncertainties on the various parameters and models. Before a complete process of probabilistic seismic hazard analysis (PSHA), with regard to uncertainties, could be carried out, we emphasize the need to study specifically some stages of the analysis to give suitable answers for the French seismotectonic context. The results presented here are released for information and discussion and are not meant to be linked to any kind of regulation. In the first section we present an overview the seismicity of France, the attenuation laws and geological conditions on the regional scale. Next, we present the seismotectonic zonation and the methodology used in this study. The last section presents the resulting maps and sensitivity tests.

\section{Estimation of Ground Motions, Macroseismic Effects, and Seismotectonic Parameters}

\section{Seismicity Catalogs}

We constituted a catalog of French seismicity for the past thousand years (Fig. 1), which is based on historical data from the SIRENE database Bureau de Recherches Géologiques et Minieres (BRGM), Electricité de France (EDF), Institut de Protection et de Sûreté Nucléaire (IPSN), and on instrumental events recorded and located by LDG since 1962. The LDG catalog consists of relocated epicenters computed from regional crustal models, in which nonnatural events have been removed (Nicolas et al., 1998). The local magnitude of LDG is presented in the Appendix. It is important to take into account both catalogs jointly because activity rates and $b$-values are better constrained from instrumental seismicity, whereas maximum magnitudes depend more on historical data. To build this catalog, historical earthquakes were ascribed magnitudes that were computed on the basis of a simple linear relationship between epicentral Medvedev-Sponheuer-Karnik (MSK) intensities and local magnitudes of LDG. We have chosen to neglect the effect of the depth because we consider that depth determination is not accurate enough for historical events; moreover, because seismicity in France is shallow $(<30 \mathrm{~km})$, it would not have a significant impact. This relation was established using the common events of the two databases since 1962 . To reduce dispersion due to uncertainty in determination of the lower intensities, only events of intensity equal or greater to the degree V-VI are considered. Dispersion remains wide for degree $\mathrm{V}$, which corresponds to local magnitudes $\left(M_{\mathrm{L}}\right)$ between 2.9 and 4.9 and represents $70 \%$ of the data. The relation inferred from the 53 remaining events is:

$$
M_{\mathrm{L}}=0.45 I_{0}+1.71 \quad \sigma=0.37
$$

where $I_{0}$ is the epicentral intensity estimated in the SIRENE database, which is either a known intensity if the epicenter coincides with an observed intensity, or an estimation from a law describing the decrease of intensity with distance from the epicenter (Levret et al., 1994, 1996).

Although the magnitude of any particular recent earthquake could be more accurately determined from the whole set of macroseismic observations (Levret, 1994; Scotti et al., 1999), we believe that this approach allows a reasonably correct estimation of the average magnitude distribution. For example, Levret et al. (1994) have proposed that local LDG magnitudes might be obtained from:

$$
M=0.44 I+1.48 \log R+0.48 \quad \sigma=0.4
$$

where $R$ stands for focal distance. If a mean depth of $10 \mathrm{~km}$ is considered, which is a reasonable average depth for the instrumental catalog, the macroseismic magnitude estimated from equation (2) is higher by 0.20 on average than the magnitude estimated from the epicentral intensity (equation 1) (Fig. 2). Equation (1) thus provides a simple way to combine the two catalogs and to estimate frequency-magnitude distribution laws.

This law also might be compared with other relationships proposed for Europe, the Mediterranean area, and Italy (Fig. 2). The comparison is not straightforward, however, because, depending on the authors, different magnitudes and different intensity scales have been used. Therefore, the comparison is just done as a qualitative exercise. The French macroseismic catalog is the only one expressed in MSK scale. Various relationships have been proposed for Italy (Tinti et al., 1986; Di Maro and Tertulliani, 1990; Albarello et al., 1995) based on the MCS intensity scale, which is very close to the MSK scale. Most of them have been estimated for local magnitude (Tinti et al., 1986). Because of different definitions, and possibly attenuation laws, the local magnitude determined in Italy differs significantly from the local magnitude determined by the LDG. Italian relationships are relatively close to that expressed by equation (1), especially the more recent one (Albarello et al., 1995) that has been established for surface-wave magnitude and epicentral or maximum intensities $\geq V$. D'Amico and Albarello (1999) recently established a relationship depending on surfacewave magnitude for earthquakes in the Mediterranean area 


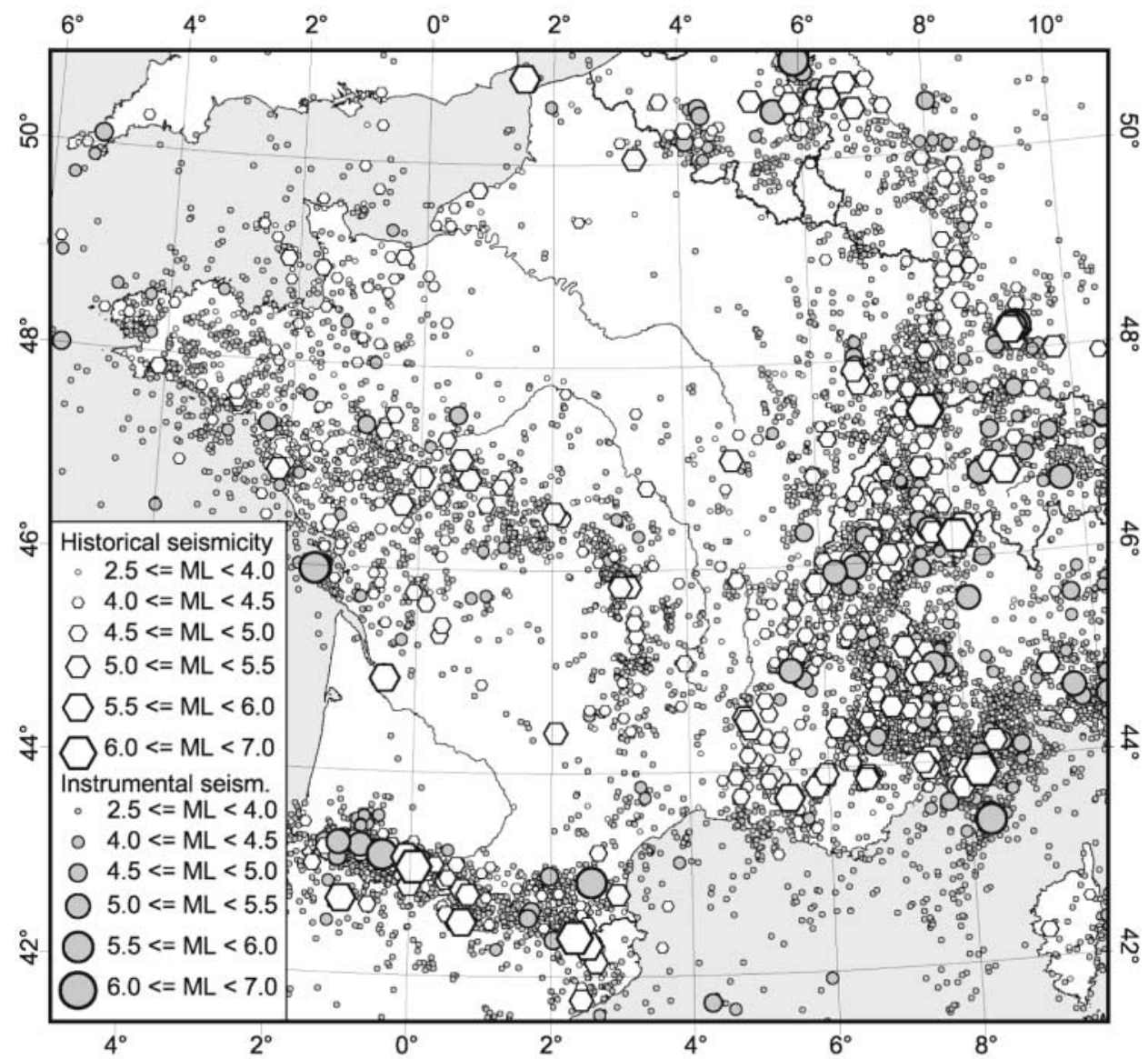

Figure 1. Historical and instrumental seismicity of France from the SIRENE (before 1962) and LDG (1962-1998) databases. SIRENE epicentral intensities are converted to local magnitudes with a simple linear relation that relies on the common events of the two databases since 1962 .

with maximum intensity $\geq \mathrm{VI}$. This relationship is also close to the one we propose for France.

The macroseismic magnitude proposed by Ambraseys (1985) has been established to match surface-wave magnitude for a northwestern European data set. The use of a surface-wave magnitude might explain the steeper slope of the relationship proposed by Ambraseys (1985) compared with other laws (Fig. 2).

\section{Attenuation Law for Peak Horizontal Ground}

\section{Acceleration in France}

A few attenuation laws have been proposed in western Europe and, in particular, in Italy. Nevertheless, the use of these relations for France is difficult particularly because of the difference in the magnitude scales. Furthermore, we will show that these laws are not consistent with the French data recently available. That is why we propose a preliminary relationship that is based on the local magnitude used for the French seismicity catalog of LDG and the range of magnitudes observed in the metropolitan territory.

A preliminary ground-motion attenuation law appropri- ate to the French context has been determined. This law was established from 14 earthquakes located in the Alps, the Pyrenees, and the Armorican Massif and recorded at short and regional distances by the LDG network (Table 1). Among these earthquakes, the two largest are the 18 February 1996, $M_{\mathrm{L}}$ 5.6, Saint Paul de Fenouillet and the 15 July 1996, $M_{\mathrm{L}}$ 5.3, Annecy events. All stations are settled on stiff bedrock. An estimation of their shear-wave velocities can be deduced from their geology settlement and leads to values between 1200 and $2000 \mathrm{~m} / \mathrm{sec}$ for carbonated formations and greater than $2500 \mathrm{~m} / \mathrm{sec}$ for the eruptive formations, which represent the majority of them. The data set represents 63 groundmotion values from vertical components of velocimeters. The horizontal peak ground accelerations (PGAs) are estimated with the empirical relation defined by Smit (1998). After least-squares adjustment, this data set yields:

$$
\begin{aligned}
\log _{10} P G A=-3.93 & \\
+ & 0.78 M_{L}-1.5 \log _{10} R \quad \sigma_{\log 10 \mathrm{PGA}}=0.55
\end{aligned}
$$

where $R$ stands for focal distance.

The law shown in Figure 3a was established for local 


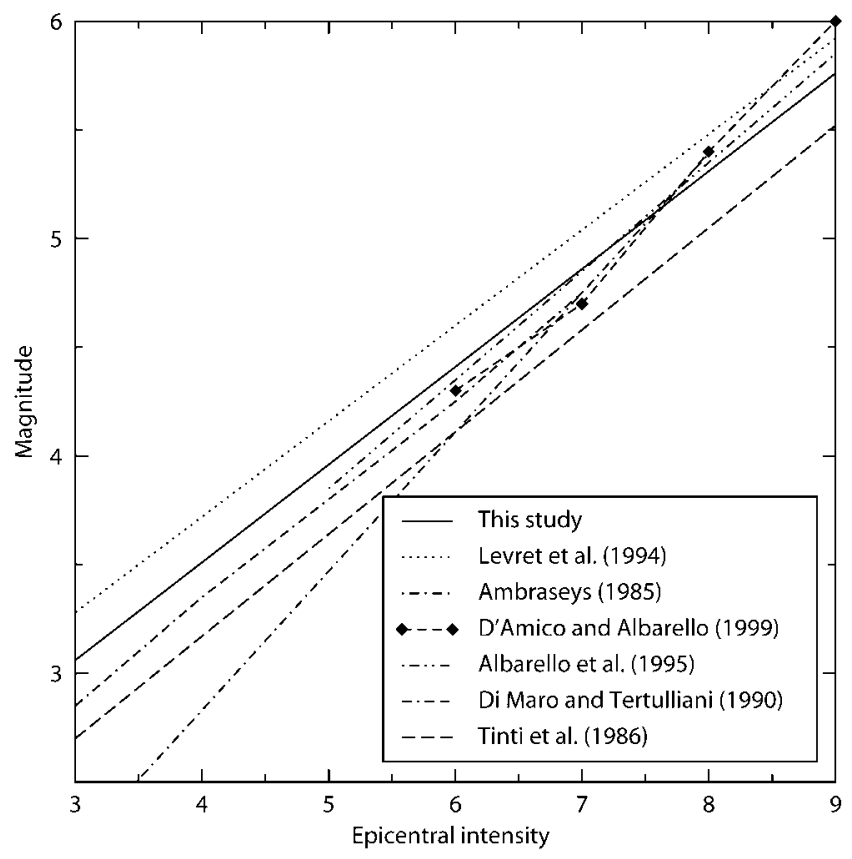

Figure 2. Relationship between local magnitude (LDG) and epicentral intensity (MSK) established for France from the common events of the SIRENE and LDG databases. This relation is compared with different relationships or correspondences proposed for the following: France by Levret et al. (1994) for local magnitudes (LDG); Northwest Europe by Ambraseys (1985) for surface-wave magnitude; Mediterranean area by D'Amico and Albarello (1999); Italy for the MCS scale (Di Maro and Tertulliani, 1990) and local magnitude (Tinti et al., 1986) or surface-wave magnitude (Albarello et al., 1995).

magnitudes between 2.6 and 5.6 and for focal distances between 5 and $700 \mathrm{~km}$. Eleven recordings concern the near field (with epicentral distances between 3 and $50 \mathrm{~km}$ ) and the whole range of magnitudes, and 34 records concern the regional field (with epicentral distances between 50 and 200 $\mathrm{km}$ ). The 18 recordings with distances greater than $200 \mathrm{~km}$ only concern the two major events of magnitudes $M_{\mathrm{L}} 5.3$ and 5.6. The relation clearly shows a good dynamic with regard to local magnitude, whereas European relationships do not.

We have compared relation (3) with Ambraseys relations (1995) obtained from European accelerometric data which have been used in recent seismic hazard studies in France (EPAS, 1998a,b). Although the EPAS group has retained the law established for a range of magnitudes between 4.0 and 7.0, we chose the law established for magnitudes 3.0-6.0 and distances between 1 and $310 \mathrm{~km}$, which we found more appropriate for the comparison. This relation is:

$$
\begin{aligned}
\log _{10} \mathrm{PGA}=-1.331 & +0.285 M_{\mathrm{S}}-0.00191 R \\
& -0.909 \log _{10} R \quad \sigma=0.3
\end{aligned}
$$

where $R$ stands for focal distance.
Ambraseys' relation is established for all geological conditions combined and he shows that, if shear-wave velocity varies from 100 to $1000 \mathrm{~m} / \mathrm{sec}$, peak accelerations decrease by a factor of 1.3. Ambraseys used recalculated surface-wave magnitudes $M_{\mathrm{S}}$. If $M_{\mathrm{S}}$ is assumed to be equivalent to $M_{\mathrm{L}}$, the attenuation law proposed by Ambraseys (1995) yields largely overestimated PGA. Surface-wave magnitude and local magnitude are not equivalent, however, particularly for events of magnitude lower than 5.5. To compare the two attenuation laws, some estimates of the correspondence between $M_{\mathrm{S}}$ and $M_{\mathrm{L}}$ were needed. In that respect, we derived an empirical relation from all earthquakes of the French catalog for which local and surface-wave magnitudes were available. The first step of the search concerned the common events of the LDG catalog and the International Seismological Centre (ISC) database for France and the surrounding areas. We obtained a set of $18 M_{\mathrm{S}}$ values coming from ISC, U.S. Geological Survey (USGS) (National Earthquake Information Service [NEIS]), Moscow (MOS), and from a few isolated stations. This poor number of values can be explained by the short period (1970-1998) and the moderate character of the French seismicity, rarely detected at more than $20^{\circ}$. To have a sample as exhaustive as possible, we added the $M_{\mathrm{S}}$ values estimated by Ambraseys for the same zone in his study of relationships for northwestern European earthquakes (1985). A set of $24 M_{\mathrm{S}}$ values was obtained for $M_{L}$ between 4.2 and 5.8 (Table 2). The scatter is significant but remains plausible (Fig. 4). The obtained relation for surface-wave magnitude values between 3.6 and 5.6 follows (Fig. 4):

$$
M_{\mathrm{L}}(\mathrm{LDG})=0.64 M_{\mathrm{S}}+2.32 \quad \sigma=0.2
$$

Ambraseys' relation is plotted in Figure $3 \mathrm{~b}$ after using equation (5), with the predictive curve proposed for France for local magnitudes 5.6, 5.3, 4.3, and 3.6. Apparently, although the magnitude has been corrected, Ambraseys' relation still overestimates the few PGAs recorded in France. The difference can reach a factor of 6 in near field $(10 \mathrm{~km})$ for magnitude 3.6 and a factor of 10 for distances of about $300 \mathrm{~km}$. Geological conditions might only partially explain the difference with French data, because Ambraseys has estimated that peak accelerations inferred from his relation (established for all geological conditions) should decrease only by factor of 1.3 , if shear-wave velocity varies from 100 to $1000 \mathrm{~m} / \mathrm{sec}$. The explanation may be the variety of magnitude scales and observations used by Ambraseys (1985) and the different seismotectonic contexts considered from the European area, the Mediterranean basin, to the Middle East.

Figure 4 shows that the difference between surfacewave magnitude and local magnitude increases with decreasing magnitude. If they are ignored, such nonhomogeneous disparities on the magnitude scale introduce systematic bias in the use of the attenuation relation. Nevertheless, the conversion between magnitude scales remains a difficult prob- 
Table 1

Earthquakes Used for the Attenuation Law Determination

\begin{tabular}{|c|c|c|c|c|c|c|}
\hline $\begin{array}{c}\text { Date } \\
(\mathrm{mm} / \mathrm{dd} / \mathrm{yy})\end{array}$ & $\begin{array}{c}\text { Latitude, }^{\circ} \\
( \pm \mathrm{km})\end{array}$ & $\begin{array}{l}\text { Longitude, }^{\circ} \\
\quad( \pm \mathrm{km})\end{array}$ & $\begin{array}{c}\text { Local } \\
\text { Magnitude }\end{array}$ & $\begin{array}{l}\text { Focal Depth } \\
\quad(\mathrm{km})\end{array}$ & No. of Data & $\begin{array}{c}\text { Shortest Epicentral } \\
\text { Distance }(\mathrm{km})\end{array}$ \\
\hline $12 / 13 / 95$ & $43.05(0.90)$ & $-0.42(1.69)$ & 2.6 & 2 & 1 & 62 \\
\hline $12 / 24 / 95$ & $47.94(0.64)$ & $-0.12(1.02)$ & 3.6 & 5 & 3 & 73 \\
\hline $12 / 29 / 95$ & $48.37(1.24)$ & 0.14 & 2.6 & 2 & 2 & 30 \\
\hline $12 / 31 / 95$ & $43.06(1.17)$ & $-0.35(1.84)$ & 3.8 & 4 & 3 & 25 \\
\hline $01 / 06 / 96$ & $43.05(1.53)$ & $-0.35(1.95)$ & 4.3 & 12 & 3 & 26 \\
\hline $01 / 06 / 96$ & $43.05(1.03)$ & $-0.39(1.48)$ & 3.9 & 6 & 3 & 27 \\
\hline $01 / 22 / 96$ & $44.47(1.39)$ & $6.82(0.70)$ & 2.8 & 2 & 2 & 87 \\
\hline $01 / 31 / 96$ & $47.72(0.81)$ & $-3.13(1.55)$ & 3.2 & 2 & 6 & 19 \\
\hline $02 / 01 / 96$ & $43.13(1.90)$ & $-0.31(2.81)$ & 3.8 & 5 & 3 & 21 \\
\hline 02/12/96 & $43.77(0.90)$ & 7.45 (1.77) & 3.0 & 2 & 2 & 28 \\
\hline $02 / 18 / 96$ & $42.83(1.11)$ & $2.53(1.14)$ & 5.6 & 11 & 10 & 8 \\
\hline $02 / 18 / 96$ & $44.76(0.65)$ & $6.74(1.38)$ & 3.9 & 2 & 2 & 3 \\
\hline $04 / 05 / 96$ & $45.26(0.76)$ & $5.93(1.18)$ & 2.8 & 2 & 6 & 35 \\
\hline $07 / 15 / 96$ & $45.93(0.49)$ & $6.09(0.82)$ & 5.3 & 3 & 17 & 68 \\
\hline
\end{tabular}

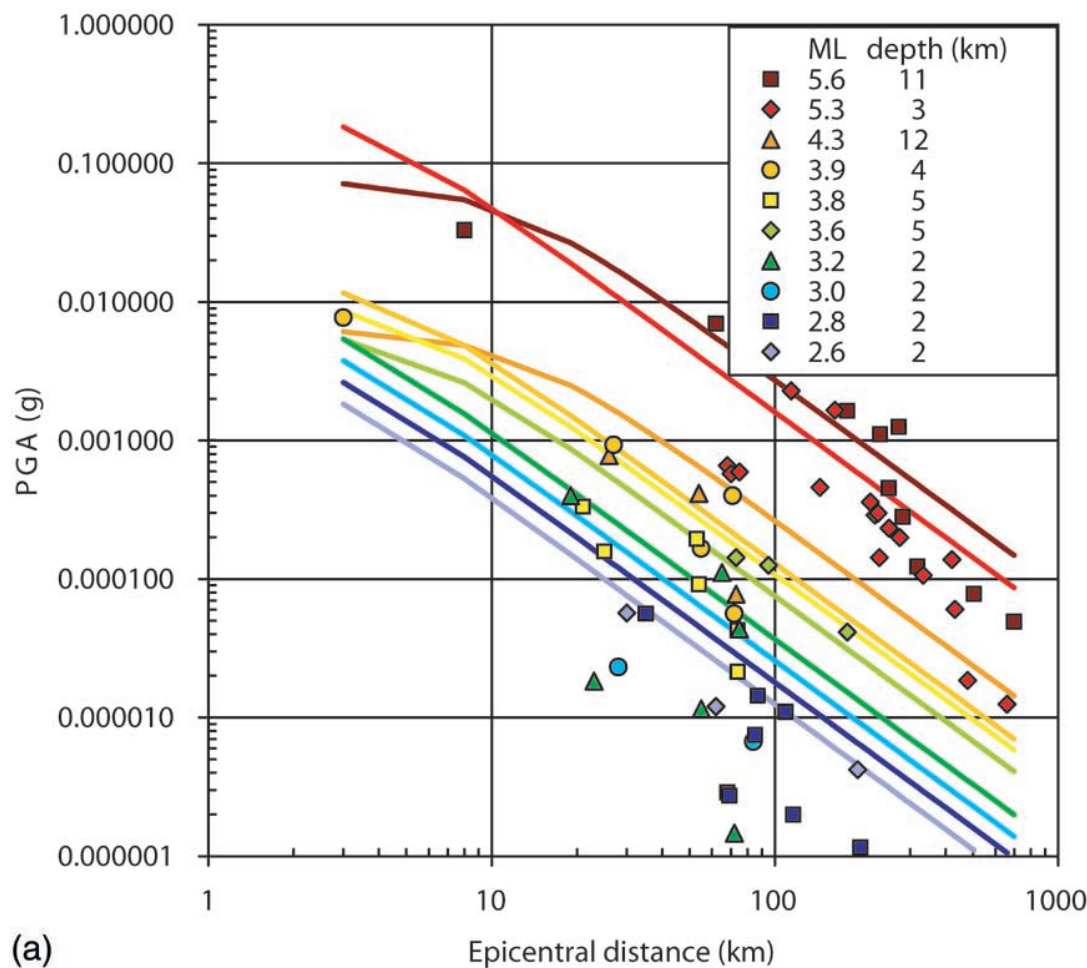

Figure 3. (a) Attenuation law of peak horizontal ground acceleration established for France from earthquakes located in the Alps, the Pyrenees, and the Armorican Massif and recorded by the LDG network (all stations are settled on stiff bedrock). The strongest magnitudes correspond to the $M_{\mathrm{L}}$ 5.6 Saint Paul de Fenouillet earthquake (18 February 1996) and to the $M_{\mathrm{L}} 5.3$ Annecy earthquake (15 July 1996), which are represented by red squares and orange diamonds, respectively. (b) Comparison of the preliminary attenuation law for France (solid lines) with the relation proposed by Ambraseys (1995) for Europe (dashed lines) for four local magnitudes between 3.6 and 5.6. (c) Comparison of the preliminary attenuation law for France with recent accelerometric data of the French accelerometric network (RAP) for local magnitudes between 4.1 and 5.9. The strongest events are the $M_{\mathrm{L}}$ 5.9 Saint Dié earthquake (22 February 2003), the $M_{\mathrm{L}} 5.7$ Lorient earthquake (30 September 2002), and the $M_{\mathrm{L}}$ 5.5 Besançon earthquake (23 February 2004), which are represented by brown squares, red diamonds, and orange triangles respectively.

(Continued on next page.) lem and might lead to systematic bias as well. The use of an attenuation relationship consistent with the magnitude scale of the French seismicity catalog, consistent with the range of observed magnitudes, even if it is established on the few data available until now, allows better estimates of the ground motion in France than the European attenuation laws.

To verify that the preliminary law is not biased because of the number of data used in the adjustment, we plot new data as soon as they become available. Figure $3 \mathrm{c}$ shows all recent events with $M_{\mathrm{L}} \geq 4$ recorded by the French accelerometric network (RAP). The strongest events are the $M_{\mathrm{L}} 5.9$ Saint Dié earthquake (22 February 2003), the $M_{\mathrm{L}} 5.7$ Lorient earthquake (30 September 2002), and the $M_{\mathrm{L}} 5.5$ Besançon earthquake (23 February 2004). The peak ground accelerations are the maximum of the two horizontal components from the accelerometers settled on bedrock. These new data show a good agreement with the predicted accelerations from relation (3) and confirm that the adjustment is adequate at the first order. Furthermore, they suggest that the relation based on the range of magnitudes observed in the metropolitan territory (from $M_{\mathrm{L}} 2.6$ to 5.6) can be extrapolated to the strongest magnitudes that could be considered in metropolitan France.

Indeed, maximum magnitudes estimated from historical seismicity are of the order of $M_{\mathrm{L}} 6.1$ to 6.3 (Southern Alps, 23 February 1887; Pyrenees, 2 February 1428). In the French 


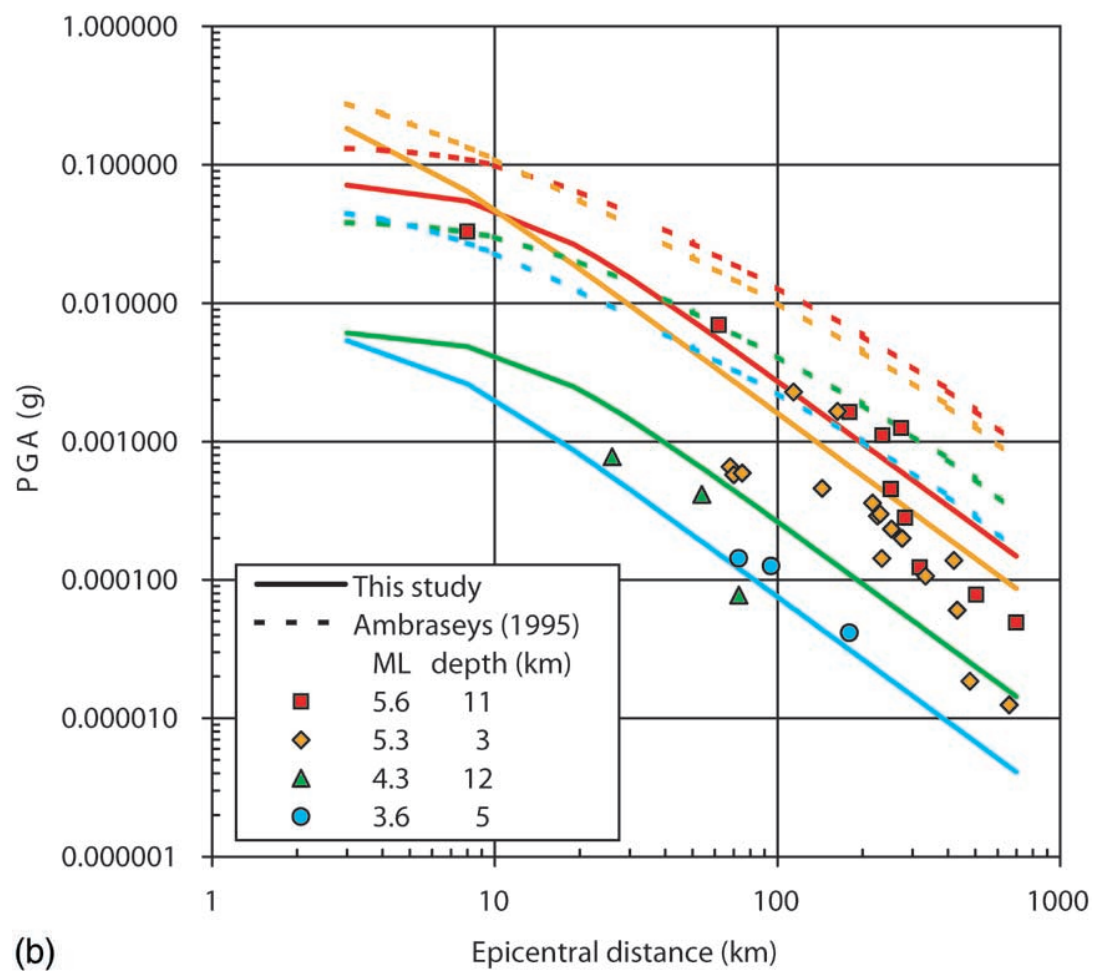

Figure 3. Continued.

(b)

Epicentral distance $(\mathrm{km})$

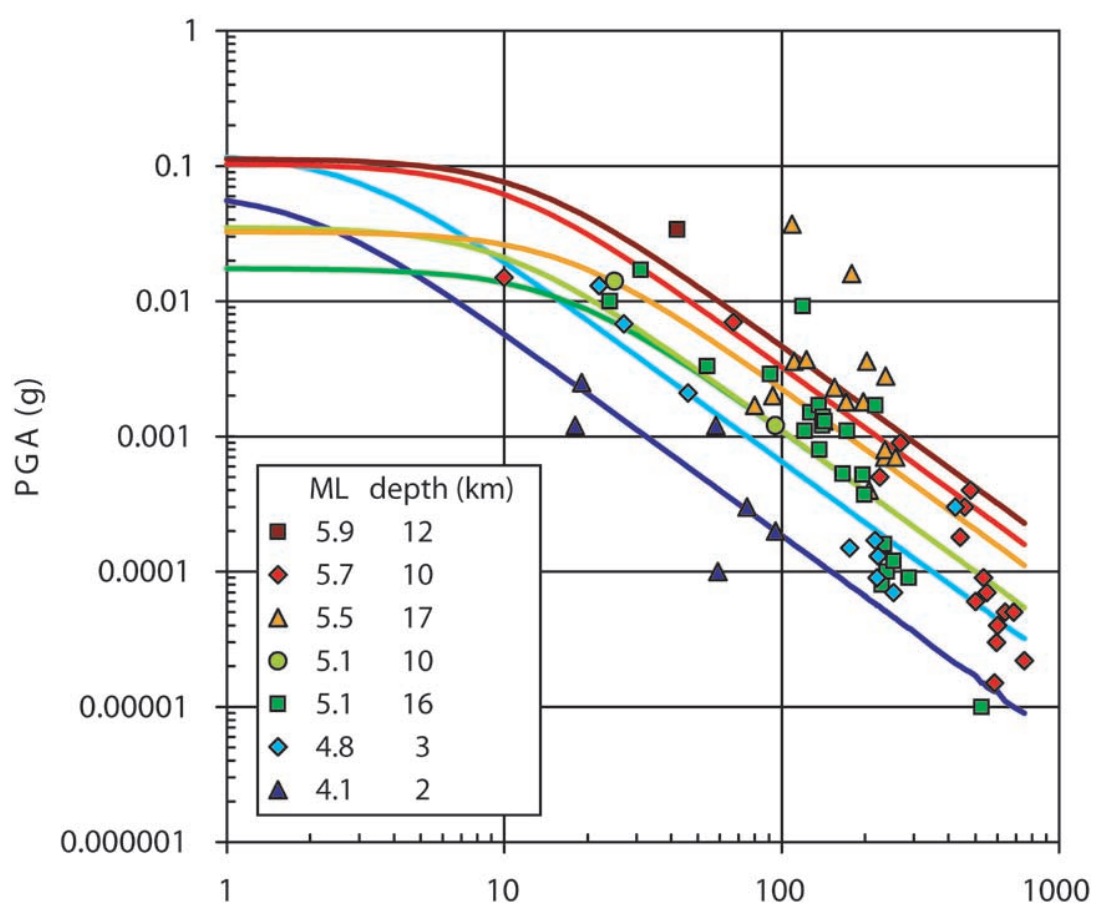

(c)

Epicentral distance ( $\mathrm{km})$

context, only few things are known about stronger events. These events have never been recorded, never been historically described, but are deduced from geological investigation and observation on a few large faults. Magnitudes inferred from paleoseismic observations are of the order of 6 to 7 . Even the faults that may produce such events are dif- ficult to characterize. These uncertainties are larger than those coming from the extrapolation of the attenuation law. Despite these uncertainties, the recent increase of knowledge about the activity of faults, mainly in Provence, cannot be ignored. Without new data, we are not able to determine the attenuation law for strong earthquakes. The choice to con- 
Table 2

Earthquakes Used for the $M_{\mathrm{L}} / M_{\mathrm{S}}$ Relationship Determination

\begin{tabular}{|c|c|c|c|c|c|c|c|c|}
\hline $\begin{array}{c}\text { Date } \\
(\mathrm{mm} / \mathrm{dd} / \mathrm{yy})\end{array}$ & $\begin{array}{l}\text { Latitude } \\
\left({ }^{\circ}\right)\end{array}$ & $\begin{array}{l}\text { Longitude } \\
\left({ }^{\circ}\right)\end{array}$ & $\begin{array}{c}\text { Depth } \\
(\mathrm{km})\end{array}$ & $\begin{array}{c}M_{\mathrm{L}} \\
\text { (LDG) }\end{array}$ & $\begin{array}{l}\text { No. of } \\
\text { Stations }\end{array}$ & $M_{\mathrm{S}}$ & Source* & $\begin{array}{l}\text { No. of } \\
\text { Stations }\end{array}$ \\
\hline $12 / 15 / 65$ & 50.69 & 4.11 & 10 & 4.4 & 3 & 3.8 & Ambraseys & \\
\hline $07 / 23 / 66$ & 50.25 & -5.16 & 23 & 4.5 & 7 & 3.6 & Ambraseys & \\
\hline $02 / 26 / 69$ & 48.30 & 9.05 & 10 & 5.1 & 15 & 4.3 & Ambraseys & \\
\hline $01 / 22 / 70$ & 48.33 & 9.02 & 20 & 5.5 & 16 & 5 & MOS & 5 \\
\hline 02/18/71 & 51.03 & 5.96 & 9 & 4.5 & 2 & 3.8 & Ambraseys & \\
\hline 09/07/72 & 45.98 & -1.49 & 11 & 5.7 & 16 & 5.5 & MOS & 15 \\
\hline $10 / 25 / 72$ & 44.52 & 9.90 & 5 & 5 & 14 & 4.3 & MOS & 2 \\
\hline $02 / 25 / 74$ & 51.66 & -3.15 & 21 & 4.6 & 5 & 3.8 & Ambraseys & \\
\hline $06 / 23 / 75$ & 50.81 & 9.96 & 0 & 5.5 & 12 & 4.8 & MOS & 1 \\
\hline $11 / 16 / 75$ & 44.64 & 9.43 & 10 & 5.1 & 15 & 4.2 & NEIS & 1 \\
\hline 09/03/78 & 48.31 & 8.96 & 8 & 5.6 & 10 & 5.3 & ISC & 7 \\
\hline 01/05/80 & 44.95 & 7.45 & 10 & 5.3 & 11 & 4.3 & ISC & 5 \\
\hline $02 / 29 / 80$ & 43.09 & -0.37 & 12 & 5.7 & 4 & 4.7 & ISC & 3 \\
\hline 01/06/82 & 43.21 & -0.98 & 15 & 5 & 6 & 3.9 & ISC & 2 \\
\hline $06 / 28 / 82$ & 50.67 & 7.90 & 0 & 4.9 & 19 & 3.6 & ISC & 2 \\
\hline $11 / 08 / 83$ & 50.64 & 5.45 & 4 & 5 & 16 & 4.4 & Ambraseys & 1 \\
\hline 07/19/84 & 52.92 & -4.27 & 9 & 5.4 & 11 & 4.7 & ISC & 2 \\
\hline $04 / 02 / 90$ & 52.32 & -2.89 & 9 & 5.2 & 23 & 4.3 & MOS & 5 \\
\hline $04 / 13 / 92$ & 51.15 & 5.82 & 11 & 5.8 & 11 & 5.6 & ISC & 31 \\
\hline 05/08/92 & 47.24 & 9.39 & 7 & 4.7 & 14 & 4.3 & MOS & 2 \\
\hline $09 / 24 / 94$ & 41.09 & 4.77 & 20 & 5 & 19 & 4.2 & ISC & 3 \\
\hline $10 / 10 / 95$ & 44.08 & 9.98 & 2 & 4.8 & 24 & 4.6 & ISC & 9 \\
\hline $02 / 18 / 96$ & 42.83 & 2.53 & 11 & 5.6 & 30 & 4.5 & ISC & 3 \\
\hline $07 / 15 / 96$ & 45.93 & 6.09 & 2 & 5.3 & 28 & 4.5 & ISC & 4 \\
\hline
\end{tabular}

$* M_{S}$ values from Ambraseys are estimated values (Ambraseys, 1985).

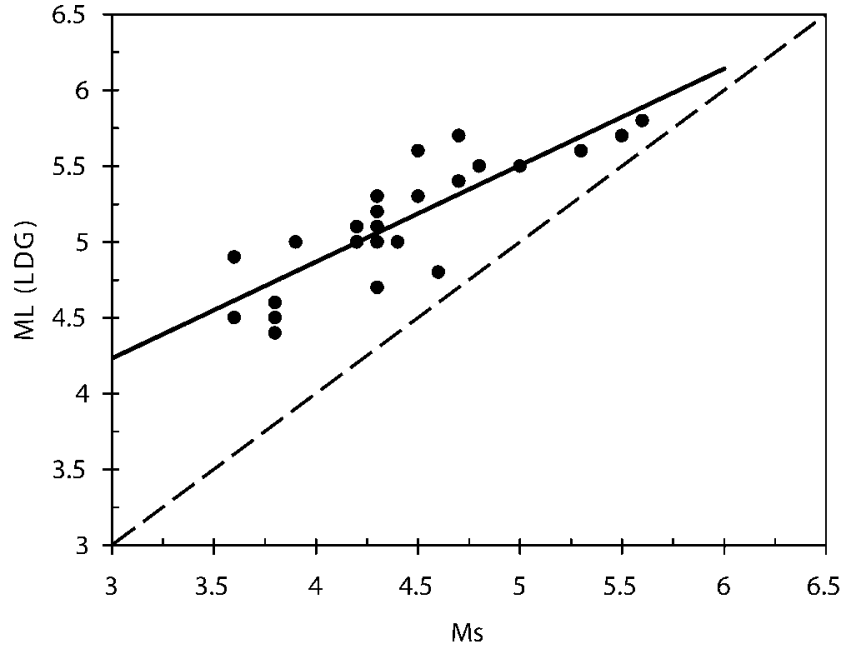

Figure 4. Empirical relation between surfacewave magnitude and local magnitude established from European earthquakes of the LDG database and Ambraseys database (1985).

sider that the attenuation law based on small magnitudes is also representative of stronger events has the advantage of being consistent over all the process. Indeed, the introduction of another relation with probably another magnitude scale will clearly not be adapted to the French data. Considering the good dynamic shown from the proposed attenuation law with regard to magnitude (Fig. 3a and c), we are confident in extrapolating the maximum magnitudes used to establish relation (3) to the maximum expected magnitudes in France.

When much more accelerometric data are available, and, in particular, in the near field, it will be possible to establish a more robust relationship. The increasing number of recordings of the French accelerometric network (RAP), in the range of useful magnitudes, will allow the establishment of such an attenuation law for the French domain.

\section{Accounting for Geological Conditions}

Local geological conditions are known to significantly affect ground motion. Because the attenuation law is established for stiff bedrock, we consider that taking geological conditions into account is essential to present results that are not globally minimized. Nevertheless, the purpose is not to deal with local and specific site effects. In a recent statistical analysis of the macroseismic database SIRENE, Bossu et al. (2000) checked for distinguishable site effects. The results indicate that no intensity amplification can be detected for formations older than $1 \mathrm{~m}$.y. and that for younger formations the average intensity increase reaches $0.6 \pm 0.2$ degree. Given that this analysis does not provide firm guidelines to attribute amplification factors to the various units forming the near-surface geology of metropolitan France, we adopted a rather generic approach. The way commonly used to deal with amplification-related geology is to consider the average velocity of shear waves for the first $30 \mathrm{~m}$ under the surface. 
Despite that it is an oversimplification, the shear-wave velocity provides an acceptable first order of classification. Of course, there is no widespread information about the real shear-wave velocity. Nevertheless, the "hardness" of sediments, and then the shear-wave velocity, increases at first order with their age mainly because of the process of compaction, sediment evolution, and surface alteration. The obtained classification has to be understood as a relative classification. Using the geological map of France at the scale 1/1,000,000 (Bureau de Recherques Géologiques, 1996), we classified surface geology in terms of "hard rock," "soft rock," and "firm soil" (Campbell, 1997; Petersen et al., 1997; Park and Elrick, 1998; Wald et al., 1999b; Wills et al., 2000):

- Hard rock: primarily Cretaceous and older sedimentary deposits, metamorphic and crystalline rock, and hard volcanic deposits (basalt);

- Soft rock: primarily Tertiary sedimentary deposits and soft volcanic deposits (ashes deposits);

- Firm soil: firm or stiff Quaternary deposits (alluvium especially) with depth greater than $10 \mathrm{~m}$.

Although the classification of geological units could be refined, these geologically defined units are expected to have distinct shear-wave velocity properties (Wills et al., 2000). Velocity characteristics remain very variable in each geological unit, but shear-wave velocity measurements and more detailed geological mapping would be necessary to account more accurately for local conditions. The map (Fig. 5) shows the distribution of the three geological condition categories derived from this simple approach at a scale suitable with the resolution of this study's results. It clearly displays the main zones where the geological conditions are expected to amplify ground motion: the Paris Basin, the Aquitaine Basin, the southeastern Basin, the Bresse Graben, the Coal Belt, the Molassic Basin, the Rhine Graben, and the Flanders Plains. The classification of geological conditions at the regional scale will provide an insight into the variability of the ground motion on the hazard maps that will not be apparent otherwise.

The amplification factors are estimated according to the reference elastic response spectrum advised for French facilities prone to seismic risk (Association Française du Génie Parasismique, 1990), as the spectral ratios of the three categories. The amplification factor at $1 \mathrm{~Hz}$ is a conservative value for the frequency range of interest. Therefore, we decided to apply this value to the PGA. Finally, the mean amplification factors used for peak horizontal ground acceleration are 2.2 for the ratio firm soil / hard rock and 1.6 for the ratio soft rock / hard rock. These mean amplification factors are close to amplification values estimated in other case studies (Boore and Joyner, 1997; Harmsen, 1997; Wald and Mori, 2000; Steidl, 2000). According to the relation linking PGA and intensity discussed in the following section (equation 6), the mean amplification factors of 1.6 and 2.2 proposed for PGA correspond to mean intensity increases of
0.5 and 0.8 , respectively. These values are consistent with the site effects suggested from the study of Bossu et al. (2000). The hazard maps obtained taking geological conditions into account show contrasts that go through the seismotectonic zone boundaries and that can even outshine them. So geological conditions are important parameters for the assessment of seismic hazard at the regional scale, even if they only represent mean amplification factors.

\section{Relationship between Intensity and PGA}

In any seismic hazard study in which historical and instrumental data are considered together there is a need for some relationship between macroseismic effects and ground motion. A common and simple assumption is that the logarithm of peak horizontal ground acceleration correlates with intensity (Ambraseys, 1974; Murphy and O'Brien, 1977; Theodulidis and Papazachos, 1992; Wald et al., 1999a; Atkinson and Sonley, 2000; Boatwright et al., 2001). We tried to establish such a relation for France. To do so, we selected a set of 37 earthquakes that produced intensities greater than VI well distributed throughout France. From macroseismic data of these events gathered in the SIRENE database and from the attenuation law predicting PGA, we obtained an estimation of the relation based on more than 8000 observations. We tested the stability of the relation for different periods from 1350 to 1960 (which is the beginning of the instrumental period for France). The result is that integration of data prior to 1900 generates a great variability when relations obtained for the twentieth century and the instrumental period are the same. This suggests that information prior to the twentieth century is probably spoilt by too large uncertainties and should be considered with caution (macroseismic surveys date from the beginning of the twentieth century). We decided to use the stable relation obtained for the instrumental period:

$$
I=10+2.3 \log _{10} \text { PGA } \quad \sigma=0.3
$$

By combining equation (6) with the PGA attenuation law (equation 3 ), the intensity should attenuate with distance from the epicenter according to:

$$
I=0.96+1.79 M_{\mathrm{L}}-3.45 \log _{10} R
$$

where $R$ stands for focal distance.

Although it has been obtained by a relatively different approach, this relationship compares relatively well with equation (2), with maximum deviations of $0,-0.5$, and -1 intensity degree, respectively, for $M_{\mathrm{L}} 4,5$, and 6 . This shows that the set of relationships proposed here is probably internally consistent.

\section{Checking the Comparison with Macroseismic Data}

A simple way to validate the laws proposed previously to account for ground-motion attenuation and geological 


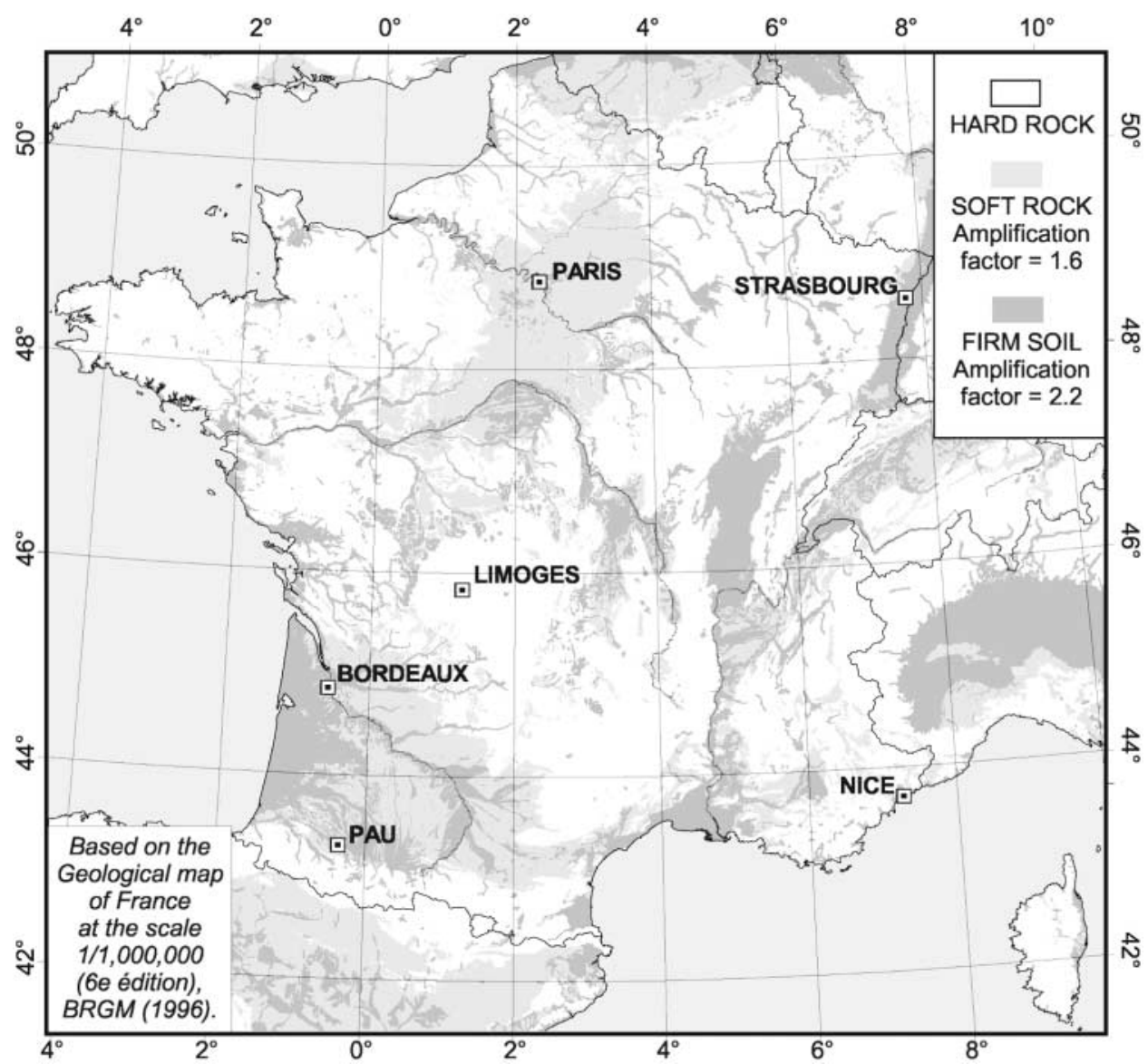

Figure 5. Geological conditions at the scale of the French national territory based on the most general classification of "hard rock," "soft rock," and "firm soil" (Campbell, 1997). Classification of geological units is based on their lithology and their age and deduced from the geological map of France at the scale 1/1,000,000 (Bureau de Recherques Géologiques, 1996).

conditions consists in comparing predicted and observed macroseismic effects for a set of events. For that purpose, we first compute peak horizontal ground acceleration, take geological conditions into account, and convert to intensity according to equation (7).

For illustration, the observed intensities and predicted isoseismals are shown for the $M_{\mathrm{L}}$ 5.7, 29 February 1980 Ossau-Arudy (Pyrenees) earthquake (Fig. 6), the largest earthquake in the instrumental catalog with well-documented macroseismic effects. Predicted intensities do not differ from observations by more than 1 degree in this particular case, and the attenuation of intensity predicted from our model seems relatively appropriate, as also seen from the plot in Figure 7a.

We have also plotted on Figure 7 the data and the predicted attenuation for two other earthquakes located in the Ossau-Arudy valley that occurred on 22 February 1924 and 22 May 1814. We note that for the 1814 event, distant effects are significantly higher than expected, compared with the effects of the 1980 and 1924 events and for similar epicentral intensities. Actually, this misfit in the apparent decrease of the estimated intensities is nearly systematic for all events before about 1900, compared with recent events of the twentieth century. Given that the attenuation in the crust cannot change through time, we attribute the changes observed in the decrease of empirical intensity through time in the database to a bias inherent in the estimation of old earthquake intensities. Indeed, at any location, the highest macroseismic effects are overrepresented, because only the most significant effects tend to be reported in historical chronicles. So, the fit of any intensity attenuation model should be based only on recent observations. We had already noticed this fact when we tried to fit the relation (6) between intensity and PGA, which was finally established only in the instrumental period. Relation (7) as a combination of equations (3) and (6) is based on: (1) instrumental data (ground motion and magnitude); and (2) the more recent data of the macroseismic database. It is therefore supposed devoid of the bias introduced by the estimation of the older events intensities. Indeed, relation (7) is in agreement with recent macroseismic data and shows that there is a bias in the older ones (Fig. 7). The estimated local magnitude of the 1924 and 1814 events are 4.9 and 5.1, respectively, according to the conversion of epicentral intensities to local magnitude (equation 1). It turns 


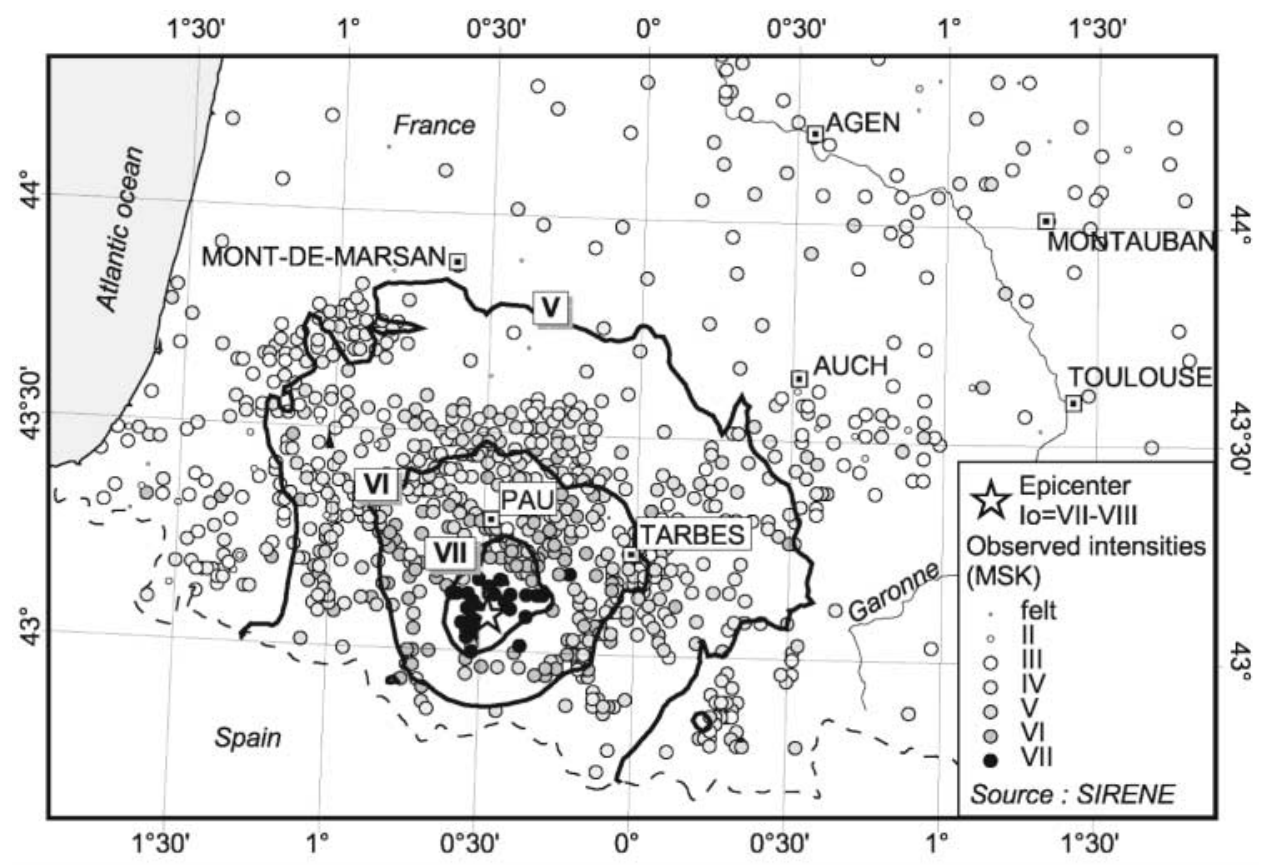

Figure 6. Comparison of observed intensities and predicted isoseismals for the 29 February 1980 Ossau-Arudy (Pyrenees) earthquake. Points are observed intensities from the SIRENE database and lines are predicted isoseismals that take geological conditions into account.

out that these estimates are probably correct to the first order in view of the whole set of macroseismic data.

We, however, made a more systematic comparison of magnitudes estimated from equation (1) and the whole set of macroseismic data. The analysis consists in adjusting local magnitude and focal depth to predict intensity according to the decrease law (equation 7), for a selection of 78 events. For the 35 historical events prior to the twentieth century, intensities reported tend to be systematically higher than expected in the range II to IV. Large misfits are also observed in the epicentral area where they might simply relate to uncertainties on the location of the epicenter. For the 18 historical and 25 instrumental events of the twentieth century, the curves fitted with magnitudes and depths that are inferred from equation (1) show a good agreement with the decrease of observed intensities. There is no systematic discrepancy in the magnitude estimated from equation (1) and in the predicted decrease law (equation 7).

The 25 instrumental earthquakes for which magnitude and depth are relatively well determined were used to check for the reliability of the magnitude that can be inferred from the epicentral intensities. We allow depth to vary of $\pm 5 \mathrm{~km}$ from the depth of the nearest instrumental events. This stage also enables the estimation of inherent uncertainties in the method. For 21 of the events, the attenuation law fitted with the instrumental parameters is in good agreement with the decrease of observed intensity. The four remaining events would be best fitted with lower magnitudes and/or with greater depths. Among them we can mention the 18 Febru- ary 1996 St Paul de Fenouillet (Eastern Pyrenees) earthquake and the 15 July 1996 Annecy (Alps) earthquake for which epicentral intensities are small (VI and V, respectively) with regard to their instrumental characteristics $\left(M_{L}\right.$ 5.6 and 5.3, respectively). A comparison of observed intensities and predicted ones for both events are presented in Figure 8. These cases show that in the lack of instrumental determination, the uncertainty on the estimated local magnitude is of the order of \pm 0.3 , if depth is constrained to vary in $\pm 5 \mathrm{~km}$ from the depth of the nearest instrumental events.

In Figure 9 we consider the 11 June 1909 Lambesc (Provence) earthquake. The Lambesc earthquake is one of the strongest earthquakes of the twentieth century felt in France. This event affected most of Provence and reached an epicentral intensity of degree VIII-IX. It is generally attributed to a surface-wave magnitude on the order of 6 (e.g., Cara et al. [1987] indicate a $M_{S} 6.3$, and in a recent study Baroux et al. [2003] propose a $M_{S} 6.0$ ). According to our modeling, the reported intensities are best fitted for a $M_{L} 5.5$ magnitude, if the focal depth is supposed to be the mean focal depth of the region $(4 \mathrm{~km})$. The map shows a good agreement for intensity degrees from V to VII and an underestimation of epicentral area corresponding to degree VIII. This may be due to Quaternary sediments that fill the Durance valley and that might be able to locally amplify ground motion beyond the mean factor that we take into account. The maximum intensity degree IX reached at Rognes and identified in the SIRENE database as site effect may be due to the local topography (Bard et al., 1992). 
(a) $1980 / 02 / 29$ earthquake $M L=5.7$

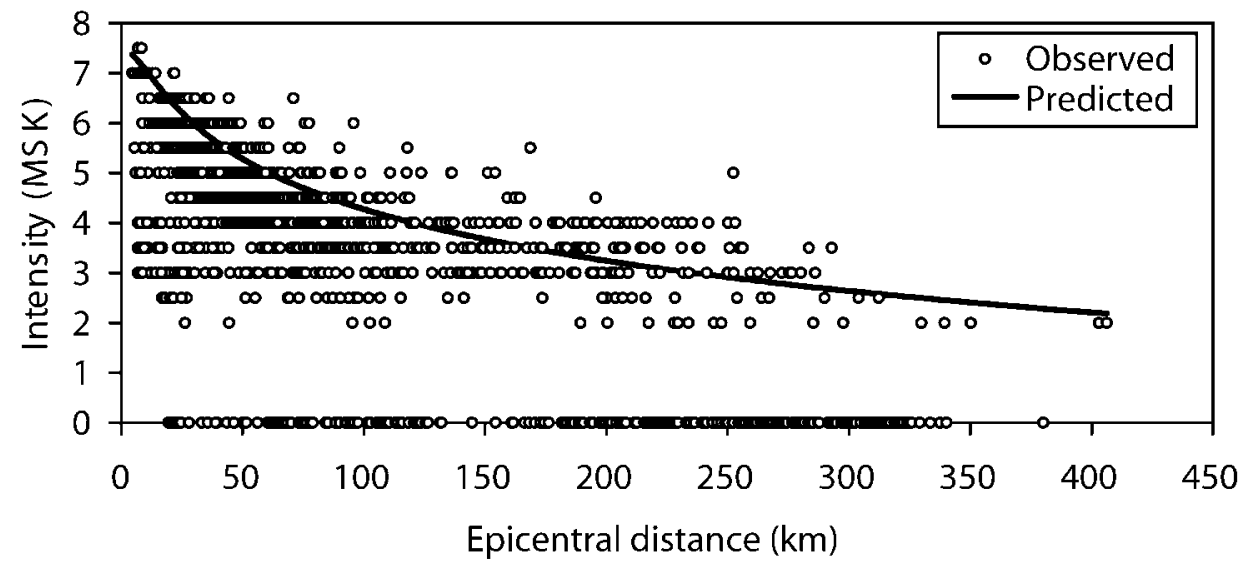

(b) $1924 / 02 / 22$ earthquake $M L=4.9$

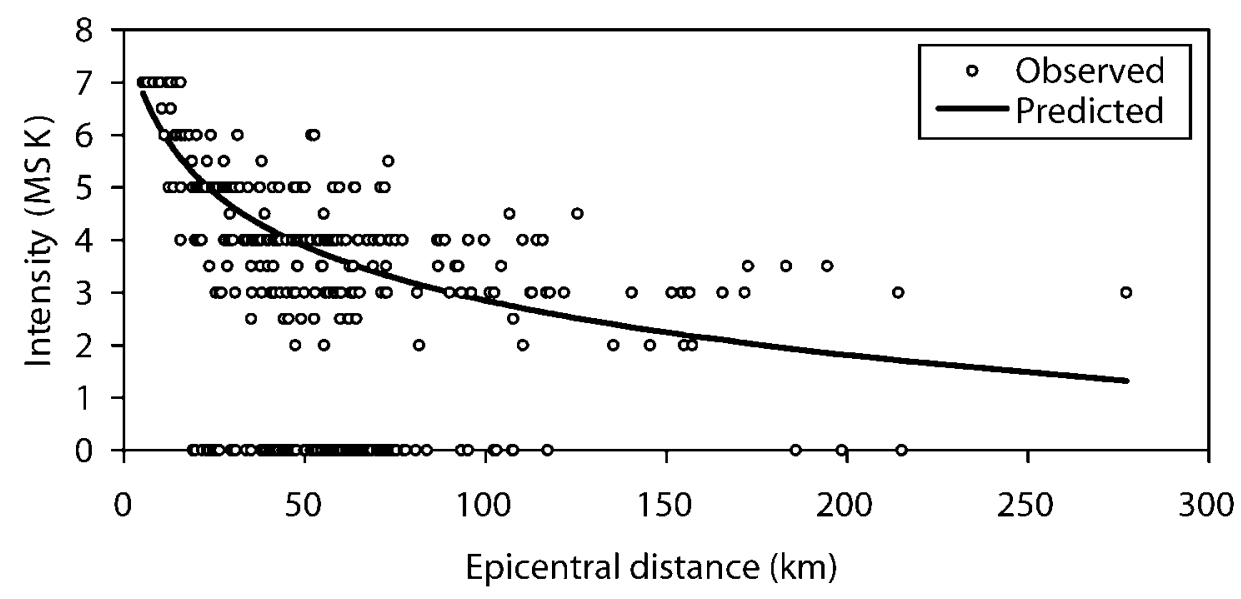

(c) $1814 / 05 / 22$ earthquake $M L=5.1$

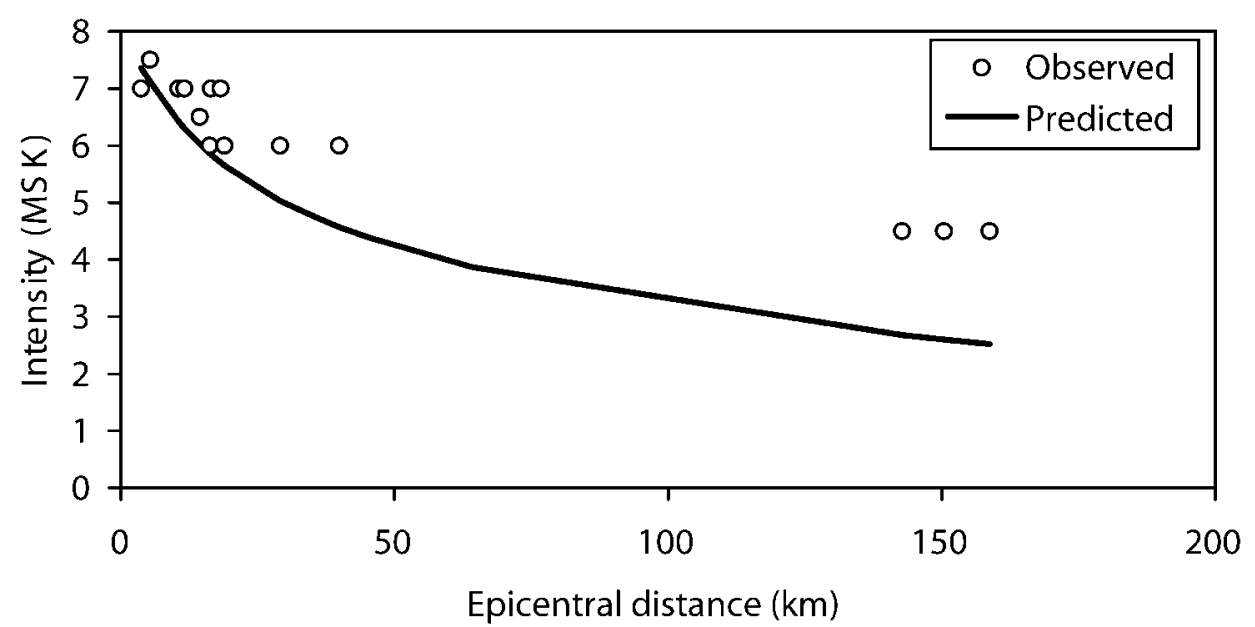

Figure 7. Comparison of observed and predicted intensities for three earthquakes of the Ossau-Arudy valley (Pyrenees). 
(a) $1996 / 02 / 18$ St Paul de Fenouillet earthquake $M L=5.6$

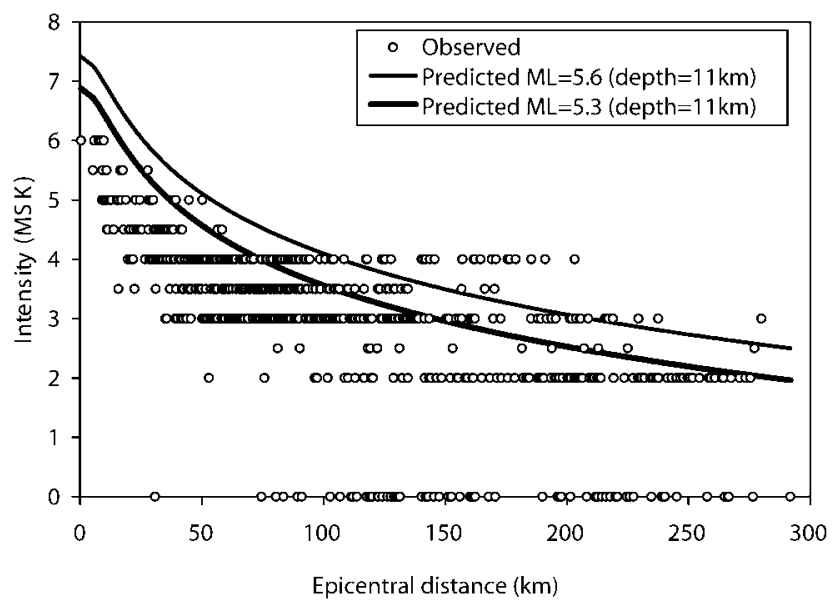

(b) $1996 / 07 / 15$ Annecy earthquake $M L=5.3$

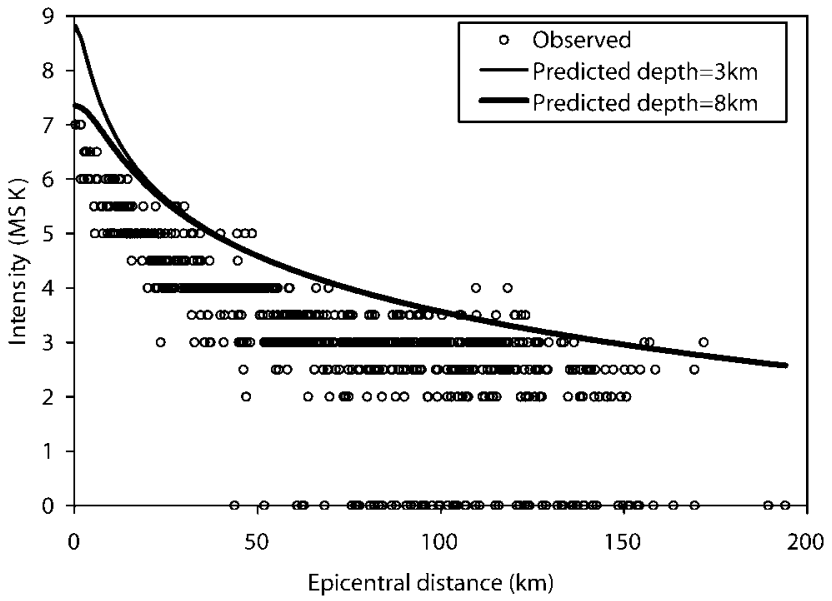

Figure 8. Comparison of observed and predicted intensities for (a) the 18 February 1996 St. Paul de Fenouillet (Pyrenees) earthquake and (b) the 15 July 1996 Annecy

(Alps) earthquake.

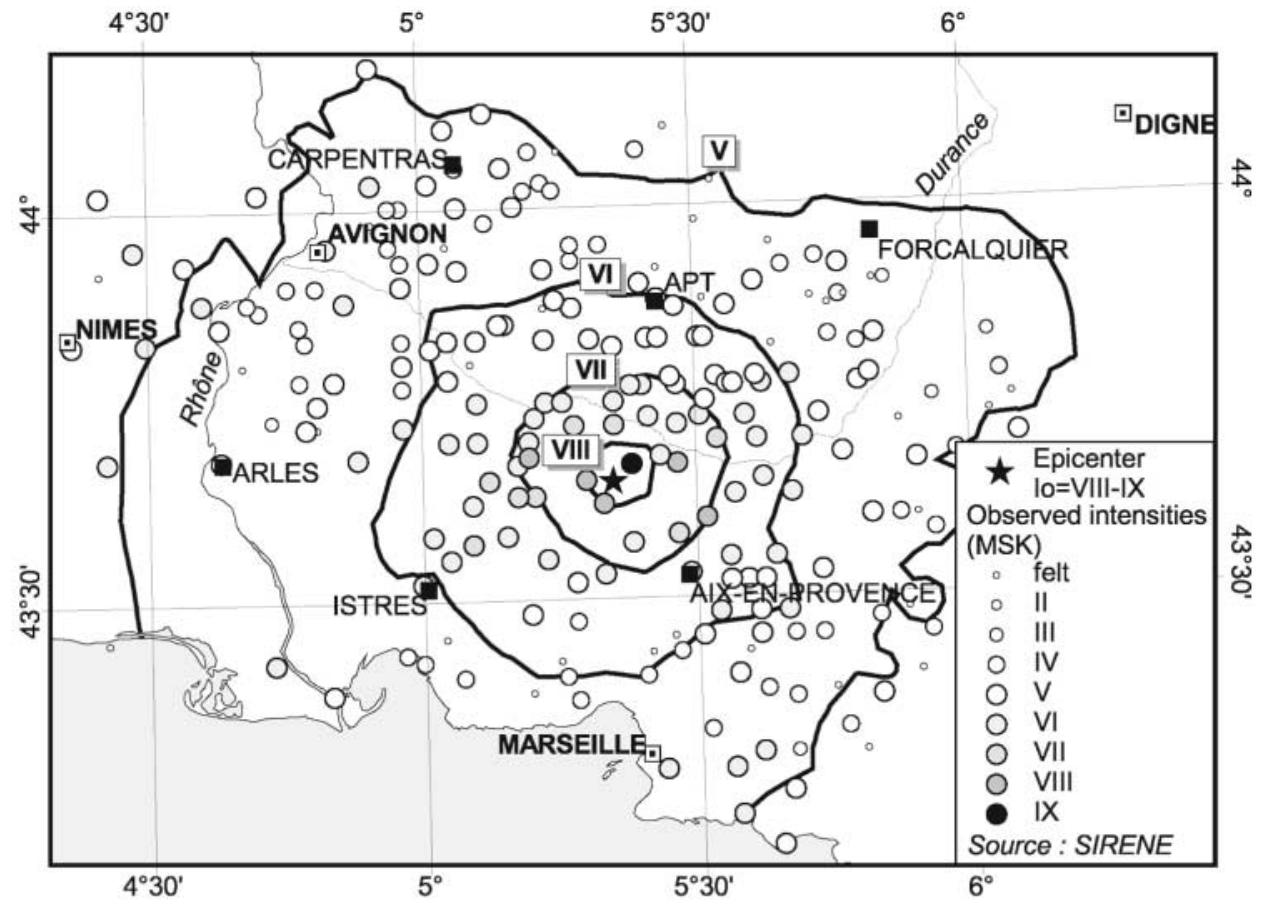

Figure 9. Comparison of observed intensities and predicted isoseismals for the 11 June 1909 Lambesc (Provence) earthquake. Points are observed intensities from the SIRENE database and lines are predicted isoseismals that take geological conditions into account.

\section{Seismotectonic Zonation of France}

We first defined a seismotectonic model consisting only of polygonal zones of assumed "diffuse" seismicity (Fig. 10). The main zones were defined so that their geodynamic behavior and their seismicity rate are different. We proposed a zonation based on the actual knowledge of the deforma- tion. At first order, it is clear that the Paris and Aquitain basins have to be separated from the adjacent regions because of their very low seismic activity. In the same way, the two main orogenic zones, the Alps and the Pyrenees, are justified by their high seismicity rates. We differentiated the Internal and the External Alps because of a strong geodynamic variation. Then we separated each of them into two 


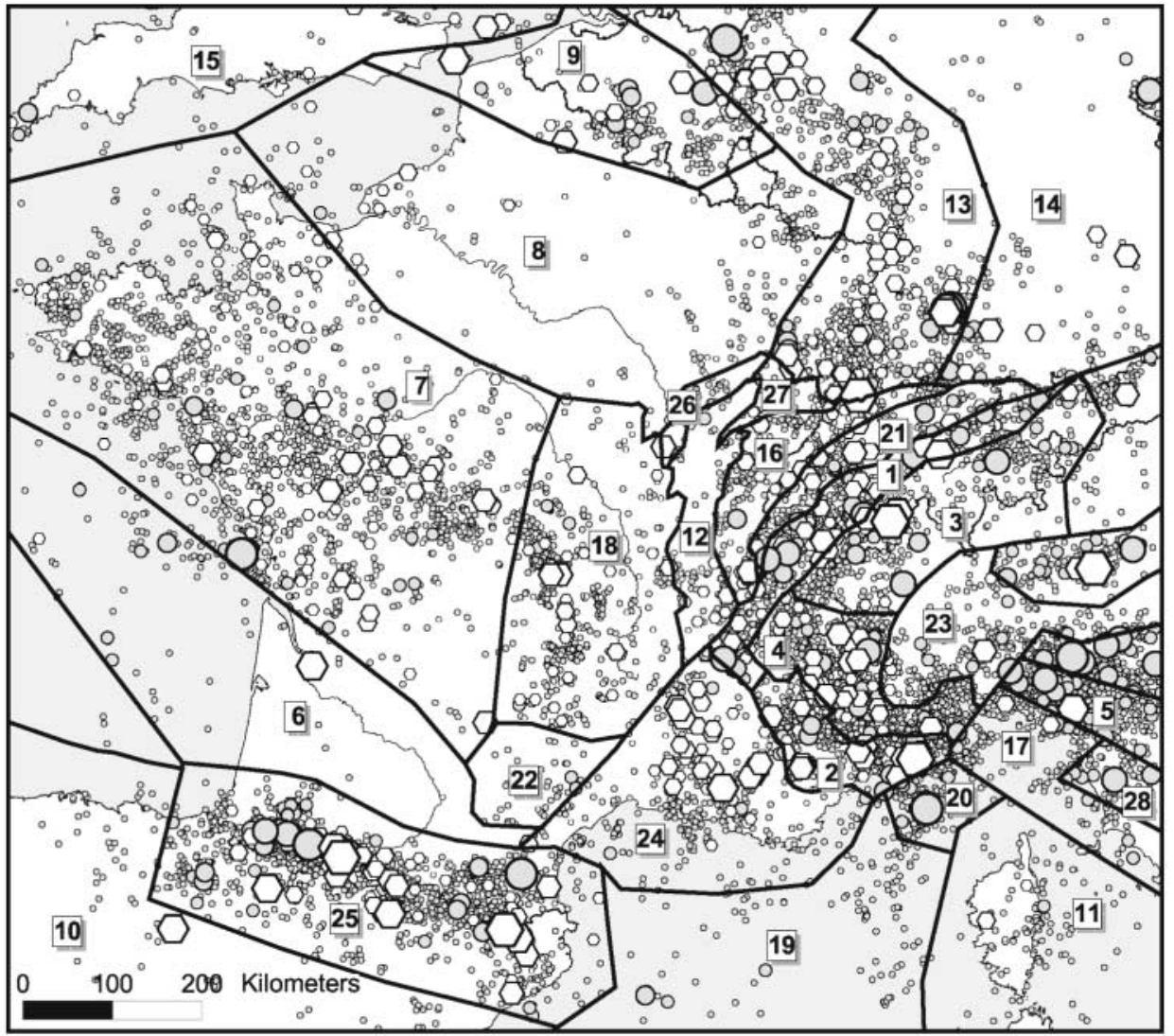

Figure 10. Seismotectonic zonation of France. 1, Northern Externals Alps; 2, Southern Externals Alps; 3, Northern Internals Alps; 4, Southern Internals Alps; 5, Apennines; 6, Aquitaine Basin; 7, Armorican Massif; 8, Paris Basin; 9, Artois-Brabant; 10, Castile; 11, Corsica and Sardinia; 12, Bresse Graben; 13, Rhine Graben; 14, Germany; 15, Ireland and United Kingdom; 16, Jura; 17, Tyrrhenian Margin; 18, Central Massif; 19, Mediterranean Sea; 20, Ligure Sea; 21, Molassic Basin and Switzerland; 22, Black Mountain; 23, Po Plain; 24, Provence; 25, Pyrenees; 26, Burgundy Sill; 27, Rhine-Saône Sill; 28, Tuscany. Legend of seismicity is the same as in Figure 1.

parts, north and south, because of variation in the observed seismicity rate. The other zones are mainly large regions where there is no clear geodynamic information to define a more detailed zonation. Only the zonation of the Pyrenees can be refined, which will be the purpose of a sensitivity test. Each zone is considered to have a rather homogeneous distribution of seismicity. The Provence is a particular case where we tried to improve the analysis by introducing a model of active faults that will be discussed later.

Each zone is characterized by a frequency-magnitude distribution (Gutenberg-Richter, 1956), which is derived from joint historical and instrumental seismicity catalogs according to the Weichert method (1980). It consists of the maximum-likelihood estimation of activity rate and $b$-value over different time periods. The instrumental seismicity catalog well reproduces seismicity of the past four decades from magnitude 2.5, which is the detection threshold of the LDG network. Nevertheless, the detection threshold has changed since the creation of the network in 1962. Indeed there is a lack of events of magnitude lower than 3.5 before 1977 .
Over a period of more than a thousand-years, the historical seismicity catalog is biased by a lack of data, particularly for low degrees of intensity. Historical seismicity is more reliable for major earthquakes. We decided to only consider events with epicentral intensity greater than or equal to VII corresponding to local magnitude 4.9. A study of the time series for the ranges of magnitude 5.0 to 5.5 and $\geq 5.5$ helps to determine their period of completeness for the whole seismicity catalog. We used the instrumental period (40 years) as the reference for the number of events for each magnitude range, which represents 15 and 7 events, respectively. The interval considered for the series is therefore 40 years. The method consists of searching for the date from which the number of events can be considered as constant. If a $50 \%$ deviation from the reference is accepted, the periods of completeness for the two magnitude ranges begin in 1840 and 1880 , respectively. Nevertheless, if we consider a particular zone, $50 \%$ of magnitudes greater than or equal to 5.0 have occurred before these dates. It means that such magnitudes in some zones have a return period greater than 150 years. 
So the periods of completeness can not really be constrained by the historical catalog considering the moderate seismic activity of the French context. To take those regional maximum magnitudes into account, we stated that the periods of completeness for the two magnitude ranges begin in 1340 and 1690, respectively. Therefore, the periods of completeness are defined for all seismotectonic zones as $M_{\mathrm{L}} \geq 5.5$ after $1340, M_{\mathrm{L}} \geq 4.9$ after $1690, M_{\mathrm{L}} \geq 3.5$ after 1962 , and $M_{\mathrm{L}} \geq 2.5$ after 1977. In practice, the method fits the slope of the Gutenberg-Richter law on the observed frequencies of low and intermediate magnitudes that represent only instrumental and reliable data. The end of the distribution, for which frequencies are estimated with a wider uncertainty, has a lower weight. The constitution of a homogeneous seismicity catalog based on the local magnitude, the definition of a zonation at a scale convenient with the probabilistic approach, and the use of the robust Weichert method, allow the estimation of reliable Gutenberg-Richter laws for all seismotectonic zones, and for the more seismic ones as for the less seismic ones.

Parameters of the Gutenberg-Richter law are shown in Table 3. Maximum magnitudes considered are the observed maximum magnitudes of the zones. Magnitudes of the strongest historical earthquakes of each zone have been systematically examined and possibly re-adjusted with the predicted decrease law (equation 7) to be in best agreement with the observed higher intensities in the epicentral area. Contrary to the deterministic approach, the maximum observed magnitude is not in itself a discriminant parameter for zonation because it does not allow differentiating regions with contrasted seismicity rates and because it does not characterize the maximum potential magnitude of the zones. A simple example is the "Southern Internal Alps" and the "Aquitaine basin" (zones 4 and 6, respectively, in Fig. 10) with fairly similar maximal known magnitudes but with strongly different seismicity rates. The determination of focal depth is generally not well constrained, but nevertheless depth is rather homogeneous within a region. We therefore determined a mean depth representative of the information available in the LDG database.

\section{Active Faults in Provence}

Active faults in France remain very poorly known, either in terms of location or seismotectonic characteristics, mainly because of the low rate of deformation. The only area where some active faults might be defined is in Provence where some quaternary deformation has been documented (Grellet et al., 1993; Lacassin et al., 1998; Baroux, 2000; Schlupp et al., 2001) even if they are still debated. We therefore made an attempt in introducing active faults in this part of France. The interest of this exercise is to refine locally the seismic hazard map and illustrate its sensitivity to changes of the seismotectonic model. The fault model proposed here is based on the recent knowledge. It is a support for the probabilistic analysis and it does not claim to be a definitive model of active faults in Provence.
Table 3

Parameters of Seismotectonic Zonation

\begin{tabular}{lcccccr}
\hline & & & & & $\begin{array}{c}\text { Maximum } \\
\text { Local }\end{array}$ & $\begin{array}{r}\text { Focal } \\
\text { Depth } \\
\text { Magnitude } \\
(\mathrm{km})\end{array}$ \\
\hline Zone & $a$-value & $b$-value & $\sigma(a)$ & $\sigma(b)$ & & \\
Northern External Alps & 3.641 & 0.938 & 0.068 & 0.027 & 5.8 & 5 \\
Southern External Alps & 4.528 & 1.198 & 0.086 & 0.034 & 6.1 & 5 \\
Northern Internal Alps & 3.427 & 0.927 & 0.084 & 0.034 & 6.1 & 7 \\
Southern Internal Alps & 4.828 & 1.207 & 0.060 & 0.024 & 5.4 & 7 \\
Apennines & 4.943 & 1.083 & 0.077 & 0.022 & 7.0 & 15 \\
Aquitaine Basin & 1.932 & 0.603 & 0.385 & 0.129 & 5.5 & 10 \\
Armorican Massif & 4.290 & 1.031 & 0.057 & 0.023 & 5.7 & 10 \\
Paris Basin & 3.252 & 1.052 & 0.279 & 0.112 & 4.9 & 10 \\
Artois-Brabant & 2.583 & 0.789 & 0.129 & 0.052 & 5.7 & 12 \\
Castile & 3.635 & 0.956 & 0.147 & 0.049 & 5.6 & 10 \\
Corsica and Sardinia & 2.014 & 0.541 & 0.345 & 0.116 & 4.8 & 10 \\
Bresse Graben & 2.620 & 0.901 & 0.381 & 0.153 & 4.6 & 10 \\
Rhine Graben & 4.023 & 0.972 & 0.050 & 0.020 & 6.0 & 7 \\
Germany & 3.717 & 1.014 & 0.346 & 0.100 & 5.3 & 10 \\
Ireland and United & 4.108 & 1.085 & 0.260 & 0.075 & 5.5 & 12 \\
$\quad$ Kingdom & & & & & & \\
Jura & 3.283 & 0.954 & 0.155 & 0.062 & 5.4 & 5 \\
Tyrrhenian Margin & 3.086 & 0.865 & 0.106 & 0.043 & 5.4 & 12 \\
Central Massif & 4.635 & 1.351 & 0.152 & 0.061 & 5.3 & 5 \\
Mediterranean Sea & 2.685 & 0.790 & 0.174 & 0.070 & 5.0 & 10 \\
Ligure Sea & 3.027 & 0.884 & 0.161 & 0.064 & 5.9 & 5 \\
Molassic Basin and & 3.276 & 0.965 & 0.174 & 0.070 & 4.6 & 12 \\
Switzerland & & & & & & \\
Black Mountain & 2.433 & 0.900 & 0.471 & 0.190 & 4.1 & 7 \\
Po Plain & 4.111 & 1.134 & 0.214 & 0.071 & 5.7 & 10 \\
Provence & 3.515 & 0.988 & 0.109 & 0.044 & 5.5 & 4 \\
Pyrenees & 4.610 & 1.062 & 0.058 & 0.023 & 6.3 & 7 \\
Burgundy Sill & 1.642 & 0.672 & 0.365 & 0.151 & 5.0 & 10 \\
Rhine-Saône Sill & 2.905 & 1.095 & 0.648 & 0.260 & 4.0 & 10 \\
Tuscany & 2.402 & 0.725 & 0.187 & 0.064 & 5.7 & 10 \\
\hline & & & & & &
\end{tabular}

Major active faults of Provence considered in this study are shown in Figure 11. They are assumed to obey the characteristic earthquake model of Schwartz and Coppersmith (1984). In this first hypothesis, we consider a model of the observed seismicity; a model for maximum possible earthquakes will be discussed later. Therefore, the characteristic earthquake is assumed to be the maximum observed one that can be associated with each fault. Faults that have produced a known historical or instrumental earthquake are characterized by the magnitudes of these earthquakes. This is the case of the Trévaresse fault that is associated with the 1909 Lambesc earthquake and of the Durance fault, associated with the strongest earthquakes of the Durance Valley. Concerning faults supposed to be active, but without any known earthquake, we stated that their characteristic earthquake is the same as similar faults in the vicinity. Faults are then composed of a number of segments that depends on the rupture length of the characteristic earthquake and on the total length of the fault. The lengths of the fault segments activated during the characteristic earthquakes are estimated according to the laws proposed by Wells and Coppersmith (1994). The return period of characteristic earthquakes associated to a given magnitude is estimated according to the frequencymagnitude law of the region of Provence established on a 


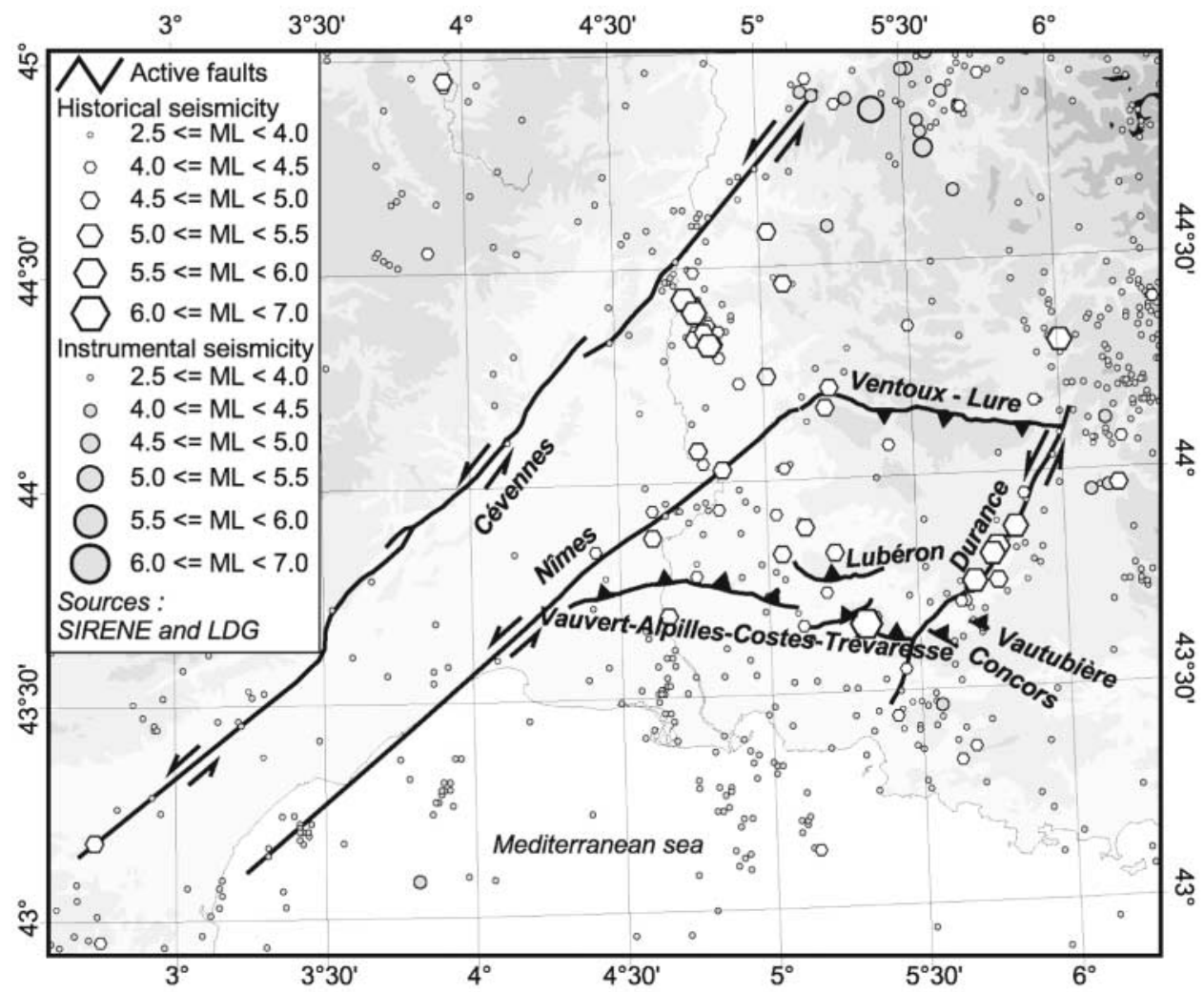

Figure 11. Seismicity and active faults considered in the Provence zone.

Table 4

Parameters of Active Faults

\begin{tabular}{lccc}
\hline Fault & $\begin{array}{c}\text { Local } \\
\text { Magnitude }\end{array}$ & $\begin{array}{c}\text { Return Period on the Fault } \\
\text { (years) }\end{array}$ & $\begin{array}{c}\text { Focal Depth } \\
(\mathrm{km})\end{array}$ \\
\hline $\begin{array}{l}\text { Central } \\
\text { Cévennes }\end{array}$ & 5.3 & 610 & 5 \\
$\begin{array}{l}\text { Northern } \\
\text { Cévennes }\end{array}$ & 5.3 & 500 & 5 \\
Southern & 5.3 & 365 & 5 \\
Cévennes & & & \\
Concors & 5.5 & 5,490 & 5 \\
Costes & 5.5 & 2,195 & 5 \\
Durance & 5.3 & 500 & 5 \\
Western & 5.5 & 1,830 & 5 \\
Lubéron & & & \\
Nîmes & 5.3 & 250 & 5 \\
Trévaresse & 5.5 & 3,660 & 5 \\
Vautubière & 5.5 & 10,980 & 5 \\
Vauvert-Alpilles & 5.5 & 785 & 5 \\
Ventoux-Lure & 5.5 & 685 & 5 \\
\hline
\end{tabular}

650-year historical period, so that the number of events predicted in the model is equal to the observed one on the same period. The return period on a fault depends on the return period of the characteristic earthquake and on the number of segments. Table 4 shows the estimated parameters of active faults. In the computation, the faults are modeled as source lines with a mean focal depth. The choice of a depth of 5 $\mathrm{km}$ is in agreement with the mean depth of the instrumental recordings of the region but, lacking of sufficient data, we are not able to make a distinction for each fault.

\section{Application of the PSHA Methodology}

\section{Probabilistic Seismic Hazard Methodology}

To assess seismic hazard at a given site, we follow the probabilistic analysis procedure established by Cornell in 1968 in a computer code developed in the LDG. The standard PSHA integrates the mean annual rate of occurrence of earthquakes over all possible earthquakes, that means over all possible locations and magnitudes in all potential seismic sources (faults and zones). Formally, the analytical expression of the mean annual frequency of exceedance of a fixed acceleration level $a$ at a given site is:

$$
\begin{aligned}
\lambda(a)=\sum_{\text {source }} v_{\text {source }} & \times \iint(m, r) \in \text { source } \\
I[\mathrm{PGA} & \geq a / m, r] f_{\mathrm{M}}(m) f_{\mathrm{R}}(r) d m d r
\end{aligned}
$$

where $v_{\text {source }}$ is the annual activity rate (the mean annual rate of occurrence of events with magnitude greater than the detection threshold in the source considered); $I[P G A \geq a / m, r]$ is the indicator function for the predicted PGA of an earthquake of magnitude $m$ and distance $r$ from the site with respect to the level $a$; and $f_{\mathrm{M}}(m)$ and $f_{\mathrm{R}}(r)$ are the probability 
density function of magnitude $M$ and distance $R$, respectively, for the source considered.

The minimum magnitude threshold used in the simulation is 3.9 for all zones. The Gutenberg-Richter law is not truncated for the maximal magnitude. The maximum distance used in the computation is $150 \mathrm{~km}$. We integrate the amplification due to geological conditions in calculation of the PGA. At this stage, we do not integrate the mean annual rate of occurrence on the variability of ground motion. Sensitivity to the ground-motion model and precisely the effect of integrating the mean annual rate of occurrence on the variability of ground motion will be discussed later.

\section{Probabilistic Seismic Hazard at a Selection of Sites}

PSHA is performed for six cities spread over the entire French territory from the most seismic regions to the least seismic ones. The locations of these cities can be seen in Figure 5. Figure 12 shows the annual probability of exceedance of peak ground horizontal acceleration for each. The cities of Nice (Southern External Alps) and Pau (Pyrenees) are equally prone to high seismic hazard in the most seismic zones of France. Afterward comes Strasbourg city (Rhine Graben). Although it is located in the less seismic zones of France, Bordeaux city (Aquitaine Margin) has higher hazard curves than Limoges city (Armorican Massif zone). This is

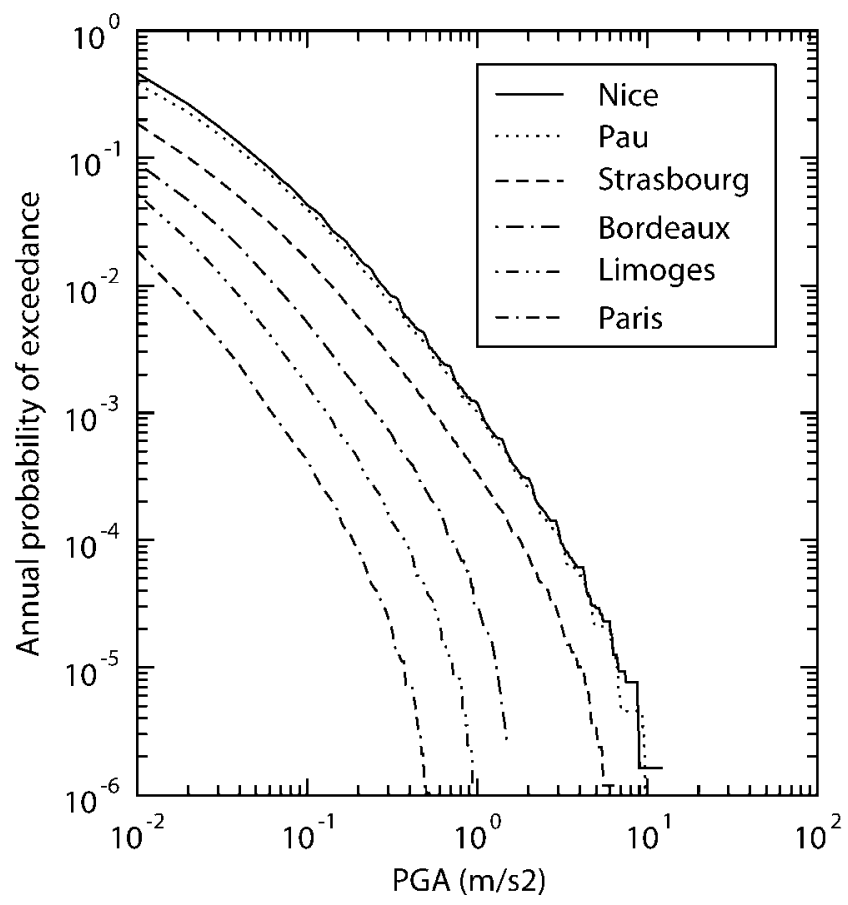

Figure 12. Distribution of horizontal PGA for six cities in France. Geological conditions are: "firm soil" for Bordeaux, Nice, Paris, Pau, and Strasbourg; and "hard rock" for Limoges.

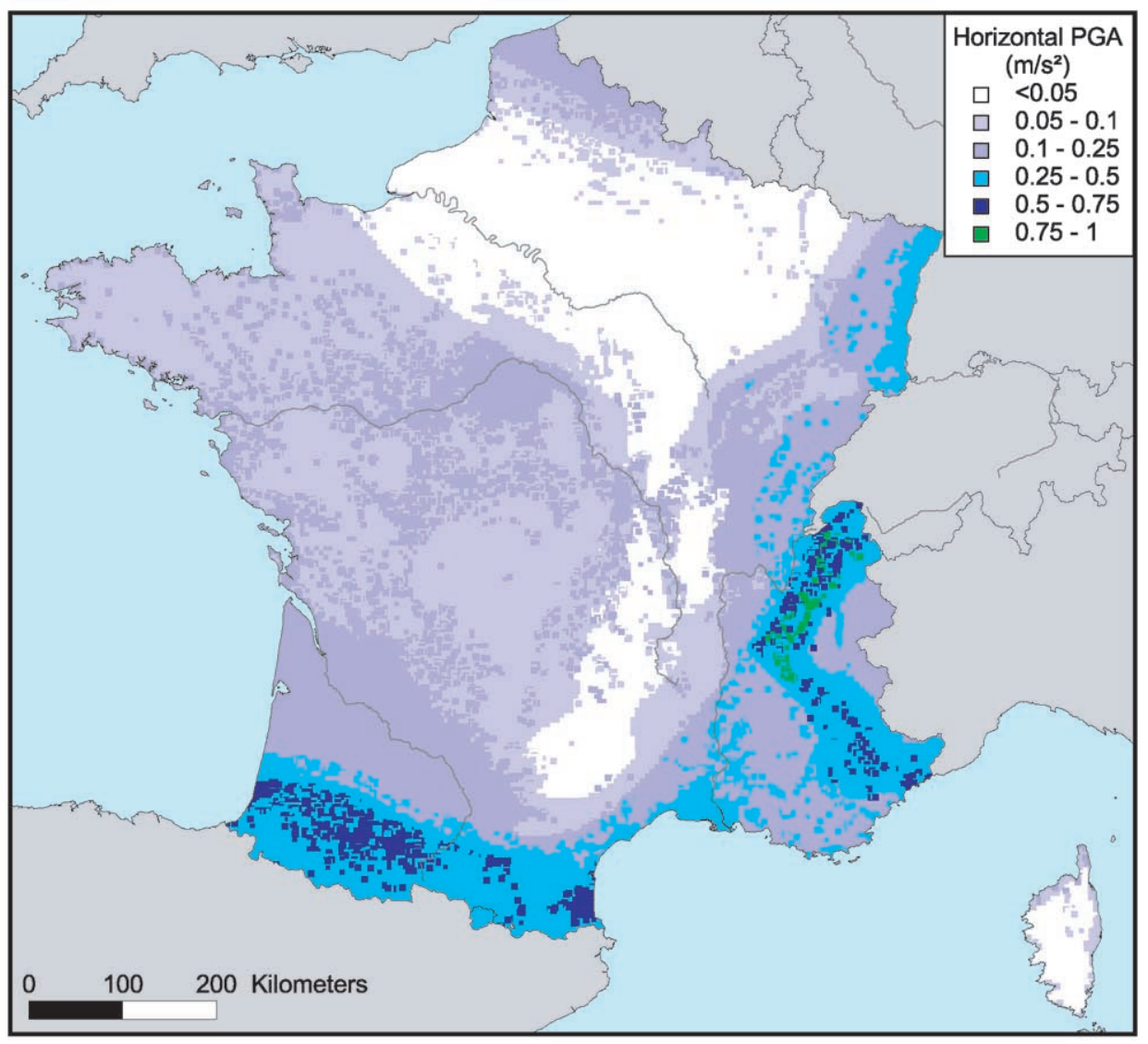

Figure 13. Expected PGA for a 475-year return period in France. 
due to geological conditions that are mainly Quaternary sediments in the great basins and rock in the Armorican Massif. It is true particularly for these two cities. Paris city (Paris Basin) is less prone to seismic hazard.

Probabilistic Seismic Hazard Maps of the Whole Metropolitan Territory

PSHA has been performed for the entire French territory for return periods of 475,975 , and 1975 years, corresponding to probabilities of exceedance of $10 \%, 5 \%$, and $2.5 \%$, respectively, in 50 years. To compute these maps, we only take into account zones of diffuse seismicity. The main features of the hazard maps reproduce zonation (Figs. 13, 14, and 15). The regions the most prone to hazard are the Alps and the Pyrenees. Maximum accelerations reach $0.90 \mathrm{~m} / \mathrm{sec}^{2}$ in the Northern Alps and $0.67 \mathrm{~m} / \mathrm{sec}^{2}$ in the Pyrenees for the 475-year return period (Fig. 13). Afterward come the regions of Alsace Plain, Jura, and Provence, where maximum accelerations reach 0.25 to $0.5 \mathrm{~m} / \mathrm{sec}^{2}$. The Aquitaine Margin, the Armorican Massif, and the Central Massif show maximum accelerations reaching 0.1 to $0.25 \mathrm{~m} / \mathrm{sec}^{2}$. Finally, the region the least prone to hazard is the Paris Basin, with accelerations less than $0.1 \mathrm{~m} / \mathrm{sec}^{2}$. The maximum accelerations displayed in all these regions are located on Quaternary or Tertiary deposits. Effects of geological conditions are ob- vious in the Armorican Massif (the Sologne especially), the Central Massif (the Coal Belt especially), the Sub-Pyrenean Basin and the Roussillon Plain, the southeastern Basin, the northern Alps, the Alsace Plain, and the Flanders Plain; where expected acceleration values can be twice as high as on hard rock. The geological conditions show contrast that goes through the seismotectonic boundaries. We emphasize on the fact that the highest accelerations reached in the northwestern Pyrenees are only due to the presence of Quaternary deposits (the seismicity has been spread over the whole zone) as well as in the northern Alps (e.g., in the Isère Valley).

The hazard map for the 975-year return period (Fig. 14) displays the same main features as for the 475-year return period. Maximum acceleration values are higher in any zone except in the Paris Basin and Provence. The variation is at most a factor of 1.7. Accelerations are the highest in the northern Alps with maximum values of $1.32 \mathrm{~m} / \mathrm{sec}^{2}$. Maximum accelerations in the Pyrenees are $0.99 \mathrm{~m} / \mathrm{sec}^{2}$.

The hazard map for the 1975-year return period (Fig. 15) displays maximum acceleration values higher than for the 975-year return period, exclusively in the most seismic zones: the Alps, the Pyrenees, the Rhine Graben, the Jura, the Central Massif, and the Provence. The highest magnitudes of these zones, which can exceed 6.0 in the Pyrenees and the Alps, have frequencies of occurrence that may sig-

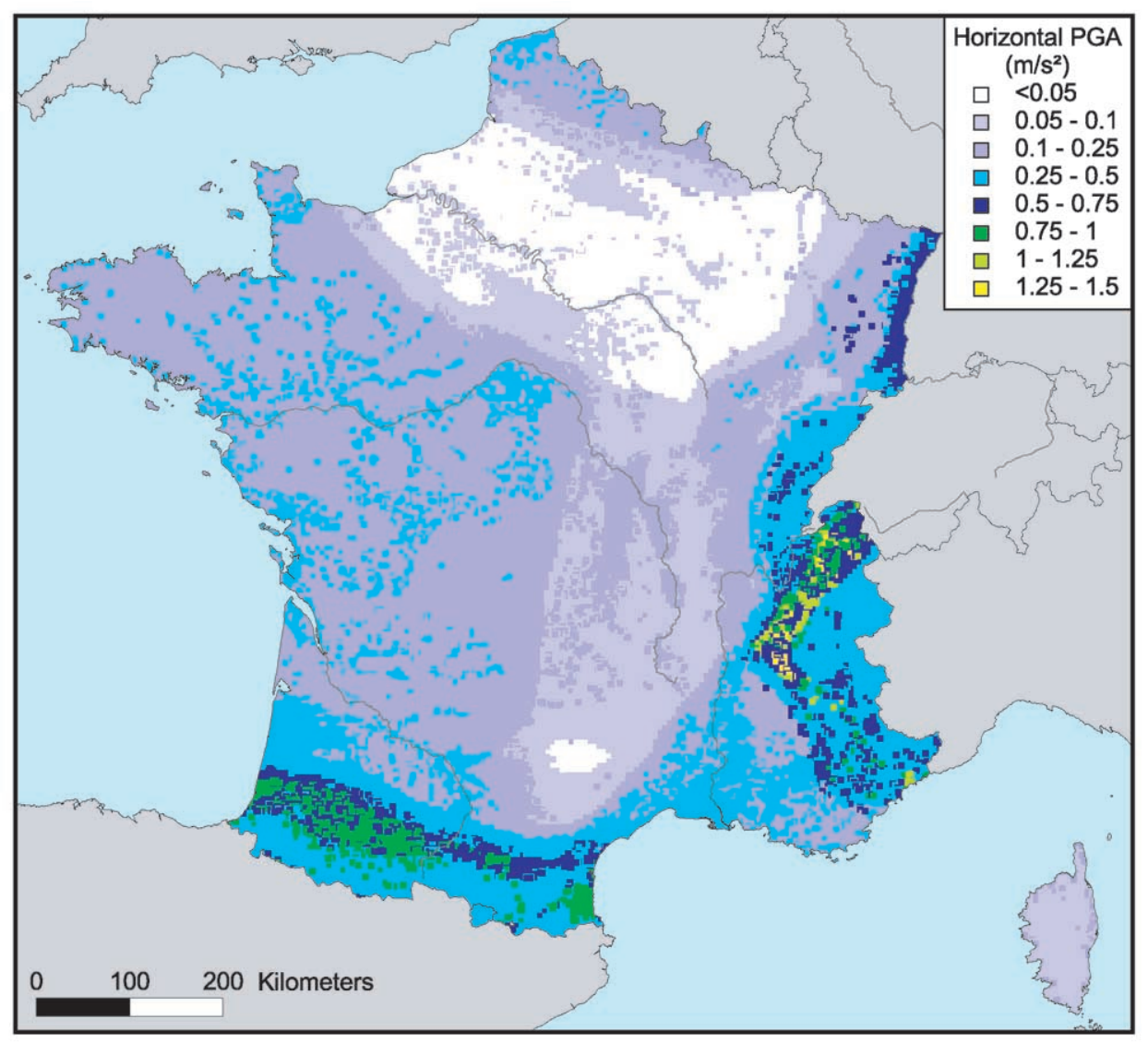

Figure 14. Expected PGA for a 975-year return period in France. 


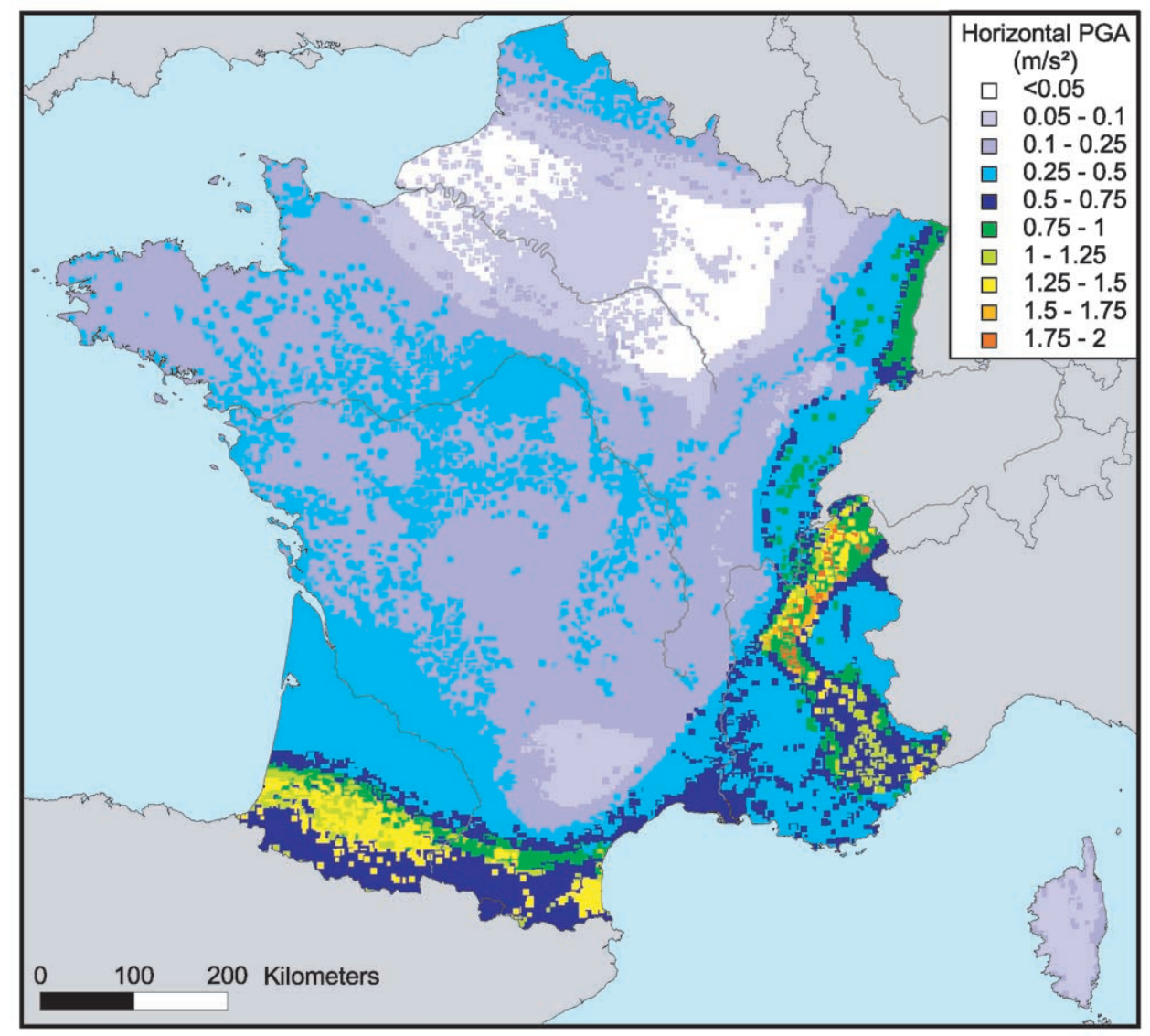

Figure 15. Expected PGA for a 1975-year return period in France.

nificantly contribute to the hazard for long return periods. The variation is at most a factor of 1.7. Accelerations are the highest in the northern Alps with maximum values of $1.86 \mathrm{~m} / \mathrm{sec}^{2}$. Maximum accelerations in the Pyrenees are of $1.44 \mathrm{~m} / \mathrm{sec}^{2}$.

To assess the consistency of the hazard maps with known seismicity, we tried to compare them with the map of PGA reached during the past thousand years. The assessment of reached PGA relies on the felt intensities of the past thousand years in France that are the only available data. The map (Fig. 16) of maximum PGA reached in France during the past thousand years is inferred from macroseismic intensities of the SIRENE database and from equation (6). For accelerations that correspond to the great majority of low and intermediate intensities, the associated return periods are lower than 1000 years, as it is to be understood from the period of completeness. So, in its main features, this map shows a good agreement with expected PGA for the 475-year return period. Acceleration levels can be compared for: the accelerations lower than $0.25 \mathrm{~m} / \mathrm{sec}^{2}$ (in the eastern and northern Paris Basin, in the Aquitaine Basin, in the Armorican Massif, in the Central Massif, and in ArtoisBrabant); the acceleration level 0.25 to $0.75 \mathrm{~m} / \mathrm{sec}^{2}$ (in the Provence, in the Pyrenees, in the Rhine Graben) and the accelerations up to $1 \mathrm{~m} / \mathrm{sec}^{2}$ (in the northern External Alps).
Accelerations greater than $1 \mathrm{~m} / \mathrm{sec}^{2}$ correspond to epicentral intensities of maximum earthquakes. Among them are the 1356 Bâle earthquake $\left(M_{\mathrm{L}} 5.7\right)$, the 1968 Oléron earthquake $\left(M_{\mathrm{L}}\right.$ 5.7), the 1980 Ossau earthquake $\left(M_{\mathrm{L}} 5.7\right)$, the 1909 Lambesc earthquake $\left(M_{\mathrm{L}} 5.5\right)$, the 1887 and 1963 Ligure earthquakes ( $M_{\mathrm{L}} 6.1$ and 5.9, respectively). These points represent a particular occurrence of events whose return period may be greater than 475 years. They should be compared with the hazard map for a 1975-year return period where such acceleration levels are reached in the Pyrenees, in Southern Alps, and even in Provence, if active faults are considered as shown in Figure 20.

\section{Sensitivity to Seismotectonic Zonation}

We used the Pyrenees as a example for the sensitivity test of the zonation. The preliminary diffuse seismicity zone is divided in a central zone and two forelands (in the north and in the south) (Fig. 17). In the Central Pyrenees zone, the activity rate is high and the strongest events occurred with a maximum local magnitude of 6.3. In the forelands, the seismicity is more sparse and moderate with maximum magnitudes of 4.4 and 5.9, respectively. The north part of Central Pyrenees is crossed by a major geological fault, the North Pyrenean Fault. The western half of this fault displays the 


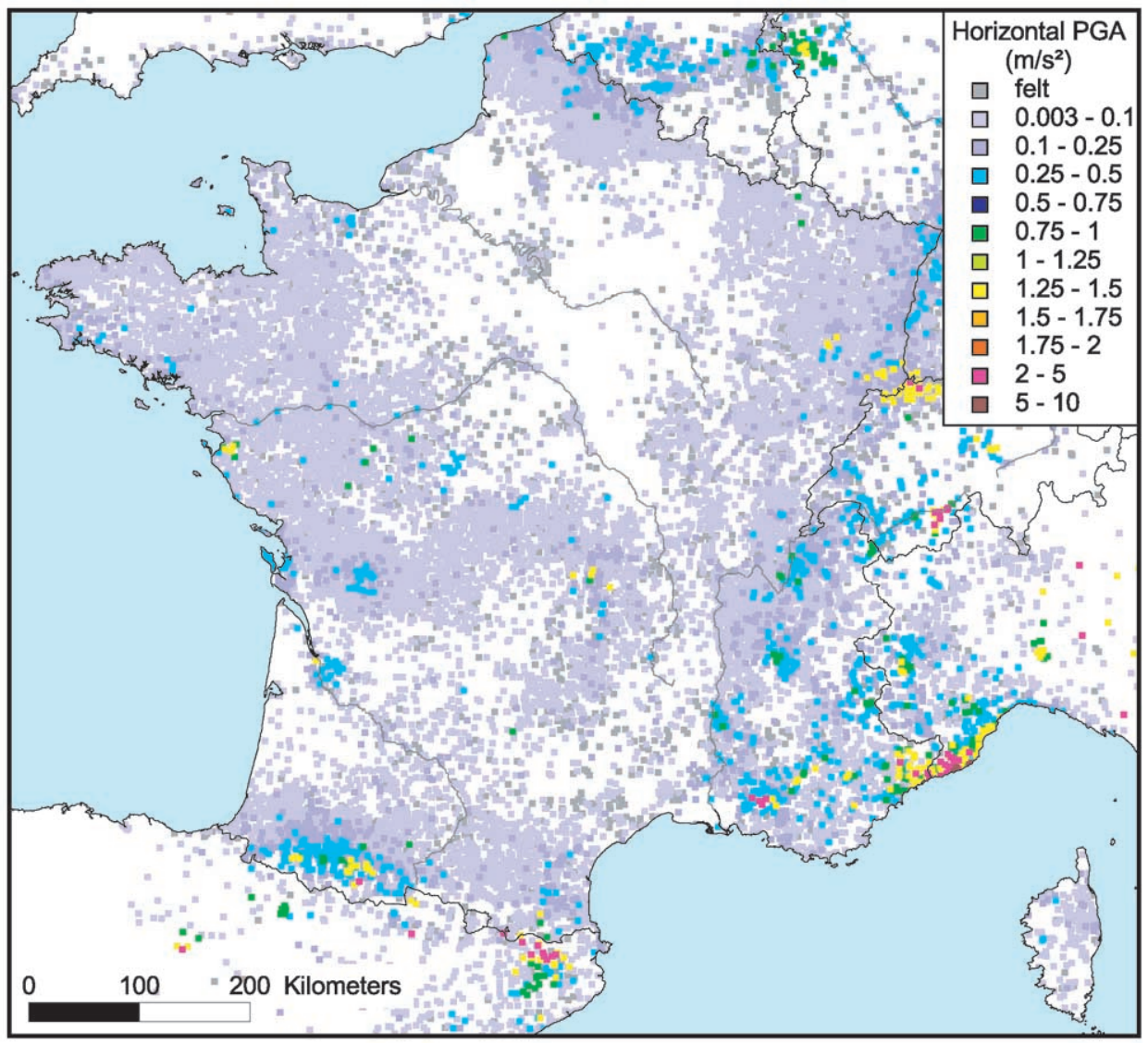

Figure 16. Assessment of maximum PGA reached during the past thousand years in France by using the SIRENE macroseismic database.

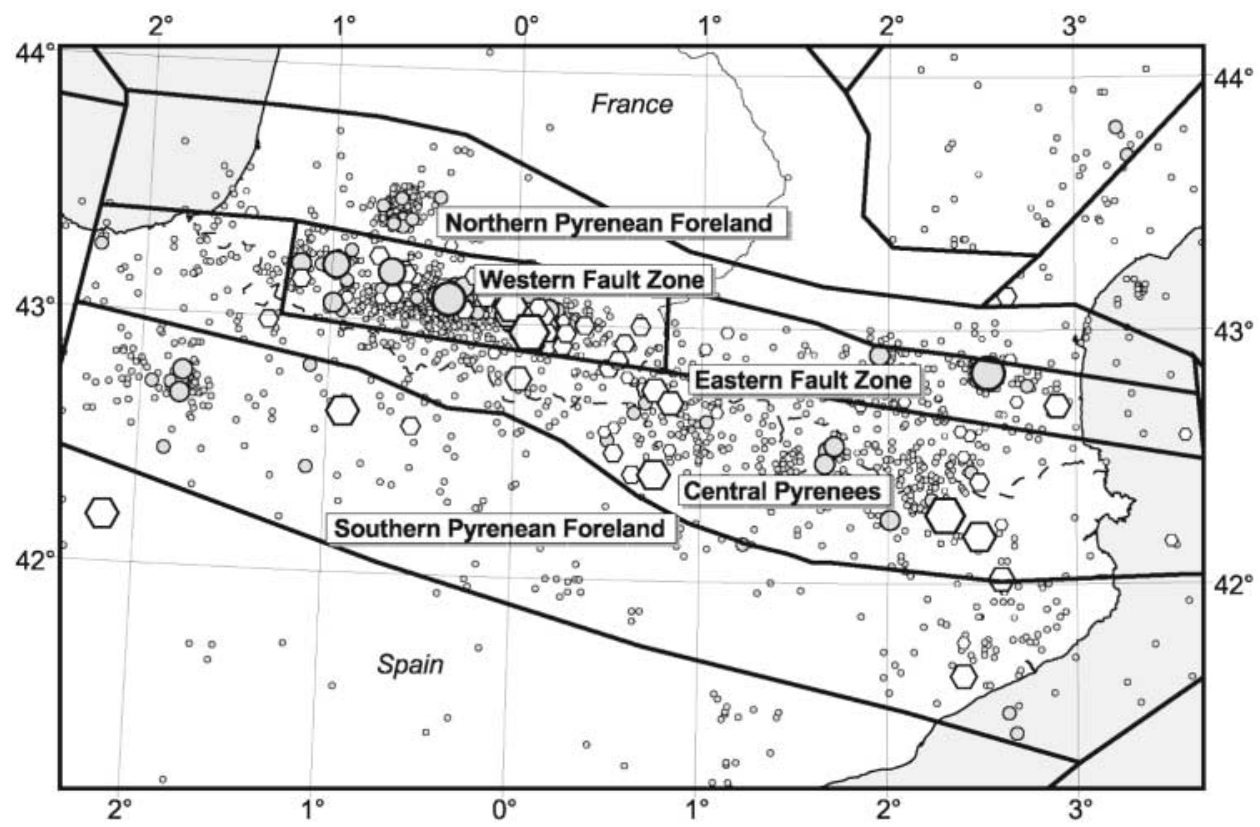

Figure 17. Detailed seismotectonic zonation of the Pyrenees. Legend of seismicity is the same as in Figure 1. 
(a) Pyrenees with 1 zone

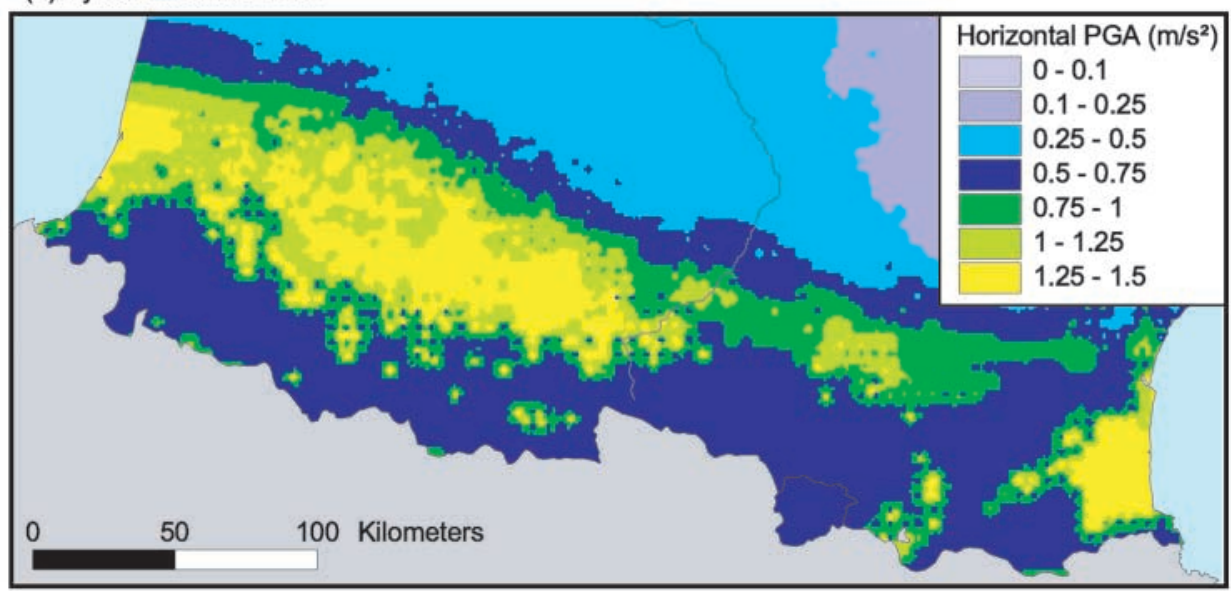

(b) Pyrenees with 5 zones

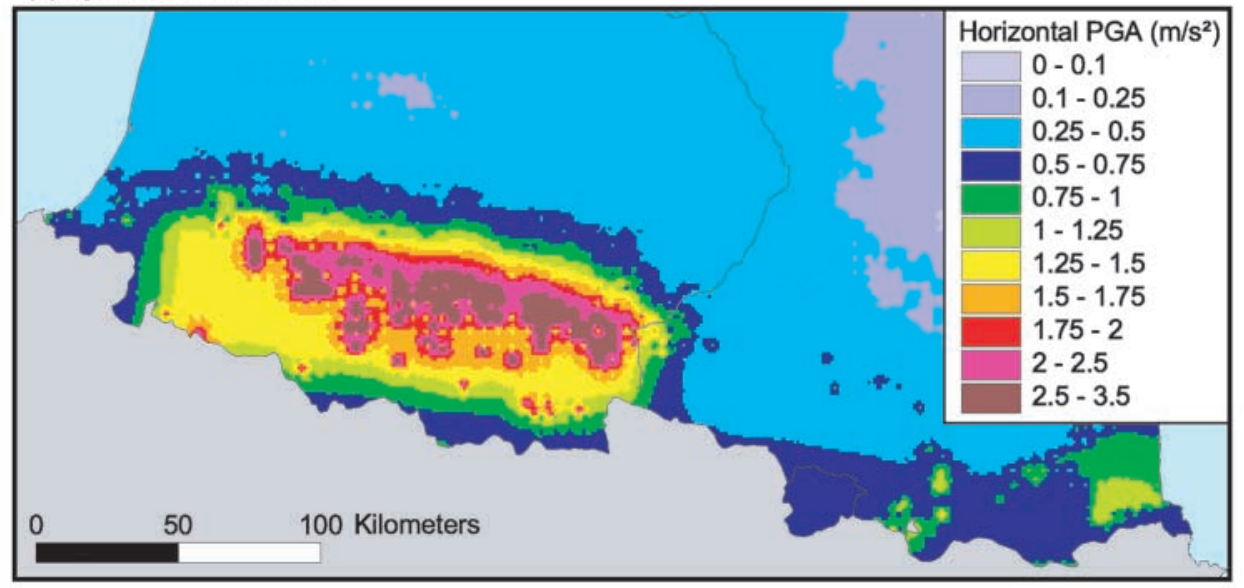

Figure 18. Effect of zonation on the expected PGA in Pyrenees for a 1975-year return period: (a) Pyrenees with one zone; (b) Pyrenees with five zones.

highest activity rate and the strongest observed magnitudes with a maximum of 6.1 , whereas in its eastern half, the seismicity rate is low and the maximum observed magnitude is 5.6. This contrast justifies the creation in the central zone of two "fault zones" (Fig. 17). The separation of the Pyrenees in five zones has the effect of confining the potential activity where it has been observed. The detailed model refines the seismotectonic model according to the knowledge of this region and it is therefore a good example for testing the sensitivity to the seismotectonic zonation. Parameters of the Gutenberg-Richter law and observed maximum magnitudes of the zones are shown in Table 5.

To evaluate the effect of zonation on the hazard, we chose the 1975-year return period, which is compatible with the frequencies of occurrence of the maximum observed earthquakes in Pyrenees. Figure 18a shows the map of the expected peak horizontal ground acceleration performed with the diffuse seismicity zone of the Pyrenees as a whole and characterized by a maximum observed magnitude of 6.3 that can occur anywhere in the zone. Figure $18 \mathrm{~b}$ is the map performed with the zonation of Pyrenees in three diffuse seismicity zones and two fault zones. The maps show an increase at most of a factor 2.5 in the Western Fault zone where the high activity has been confined. In the Eastern Fault zone and in the forelands, a decrease at most of a factor 0.2 is observed. This contrast is explained by the relative contributions of the two fault zones. It is emphasized by the presence of Quaternary deposits in the Western Fault zone that explains the highest acceleration values. The highest accelerations do not exactly correspond to the fault zone, but

Table 5

Parameters of Detailed Seismotectonic Zonation of Central Pyrenees

\begin{tabular}{|c|c|c|c|c|c|c|}
\hline Zone & $a$-value & $b$-value & $\sigma(a)$ & $\sigma(b)$ & $\begin{array}{l}\text { Maximum } \\
\text { Local } \\
\text { Magnitude }\end{array}$ & $\begin{array}{c}\text { Focal } \\
\text { Depth } \\
(\mathrm{km})\end{array}$ \\
\hline Pyrenees & 3.820 & 1.025 & 0.083 & 0.033 & 6.3 & 7 \\
\hline Western Fault & 4.234 & 1.030 & 0.050 & 0.020 & 6.1 & 7 \\
\hline Eastern Fault & 3.799 & 1.158 & 0.212 & 0.085 & 5.6 & 7 \\
\hline $\begin{array}{l}\text { Northern Pyrenean } \\
\text { Foreland }\end{array}$ & 3.068 & 0.916 & 0.088 & 0.035 & 4.4 & 7 \\
\hline $\begin{array}{l}\text { Southern Pyrenean } \\
\text { Foreland }\end{array}$ & 3.400 & 0.916 & 0.088 & 0.035 & 5.9 & 7 \\
\hline
\end{tabular}


to the regional geological conditions in the North of this zone.

\section{Effect of Active Faults in the Seismicity Model}

We used Provence as another case example for sensitivity tests of the seismotectonic model. The aim in introducing a model of active faults is to refine locally the seismic hazard map. The diffuse seismicity zone of Provence is characterized by a maximum observed magnitude of 5.5 , which can occur anywhere in the zone. The model of active faults previously described is then included as potential sources. We consider that the strongest events of the zone $\left(M_{\mathrm{L}} 5.5\right.$ and 5.3) are associated with these faults as representative of their characteristic earthquakes. In that case, the maximum magnitude of the remaining diffuse seismicity in the Provence zone is 5.1. To evaluate the effect of active faults on the hazard, we chose the 1975-year return period which is compatible with the frequencies of occurrence of the characteristic earthquakes. The maps of expected peak horizontal ground accelerations have been performed without (Fig. 19) and with (Fig. 20) the model of active faults in the region of Provence. The maps show an increase of accelerations in the vicinity of faults and a decrease in the background. Variations are at most of a factor 3 in the vicinity of faults and of a factor 0.7 in the background. As a long return period is used and the associated strongest events are localized on the faults, the highest accelerations are concentrated near the faults. The highest accelerations are reached along the Nîmes, Vauvert-Alpilles, Costes, Trévaresse, and Durance faults where quaternary alluvial sediments induce amplification. For example, the maximum acceleration of $1.78 \mathrm{~m} /$ $\sec ^{2}$ reached in the south of Nîmes city can be explained by the simultaneous contributions of the Nîmes and Vauvert faults together with most unfavorable geological conditions.

PSHA easily enables the consideration of a hypothesis based on the input assumptions of the seismicity model, such as the size and the recurrence of maximum magnitude of each source. We studied the possibility of integrating the occurrence of a scenario such as paleoearthquakes in the model of active faults to improve long-term hazard assessments in the region of Provence. In Table 6, we considered possible maximum magnitudes compatible with magnitudes estimated from paleoseismic data (Combes et al., 1993).

In this hypothesis, the Vautubière fault was excluded because its length may not produce an earthquake of a magnitude greater than 5.5, which is, in the hypothesis of paleoearthquakes, the maximum magnitude of the diffuse seismicity zone of Provence. As in the model of the observed seismicity, the return period on a fault depends on the return period of the characteristic earthquake and on the number of segments liable to produce the characteristic earthquake. Return periods of characteristic earthquakes are estimated from the Gutenberg-Richter law of Provence extrapolated up to magnitudes of 7.0. The effect of paleoearthquakes on the hazard map of the Provence region is shown for the 1975year return period (Fig. 21). This map can be compared with Figure 20. As the characteristic magnitudes associated with the faults increase, their return periods got longer. Therefore, the effect of the Cévennes, Durance, and Ventoux-Lure faults disappears (their characteristic earthquakes have return periods of ten thousand years) while the map displays the contributions of Nîmes, Vauvert-Alpilles, Lubéron, and Costes-Trévaresse faults. (Their characteristic earthquakes

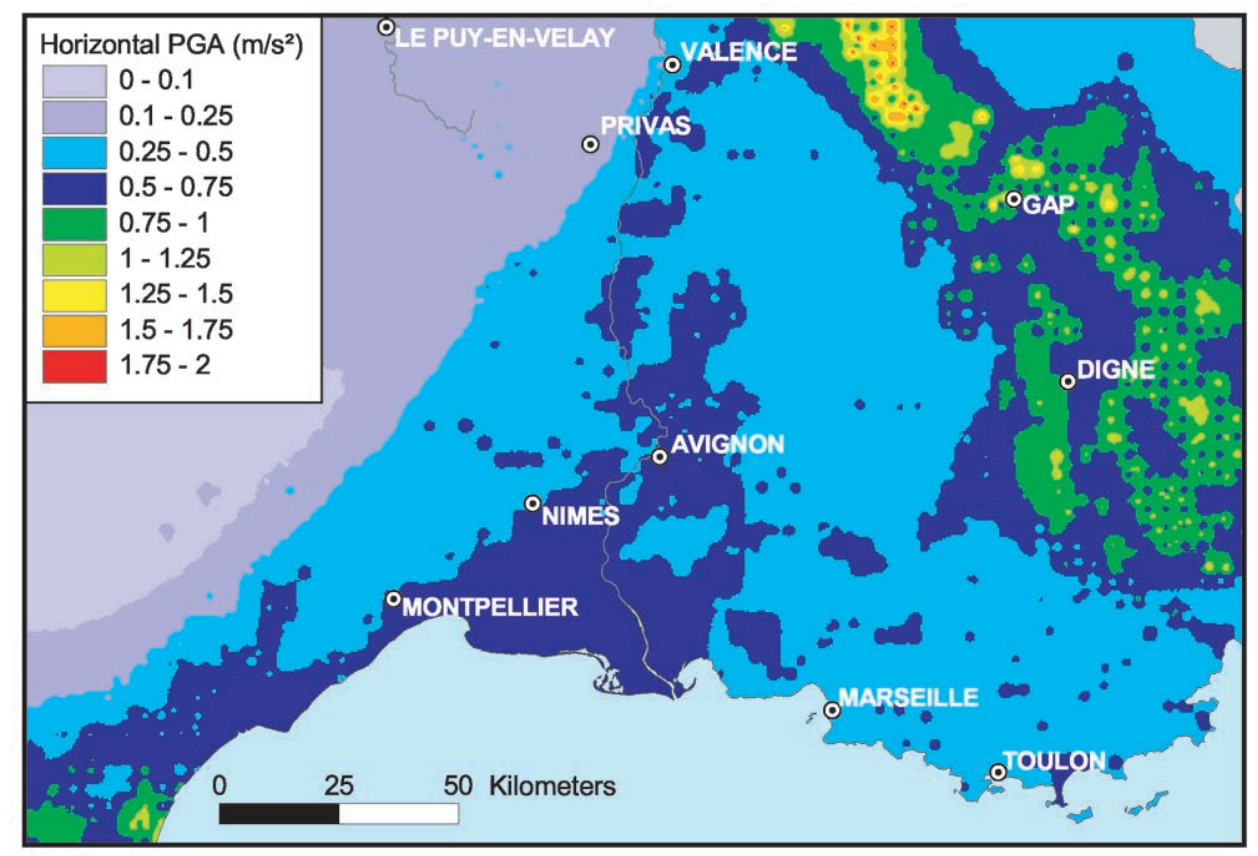

Figure 19. Expected PGA in Provence for a 1975-year return period. 


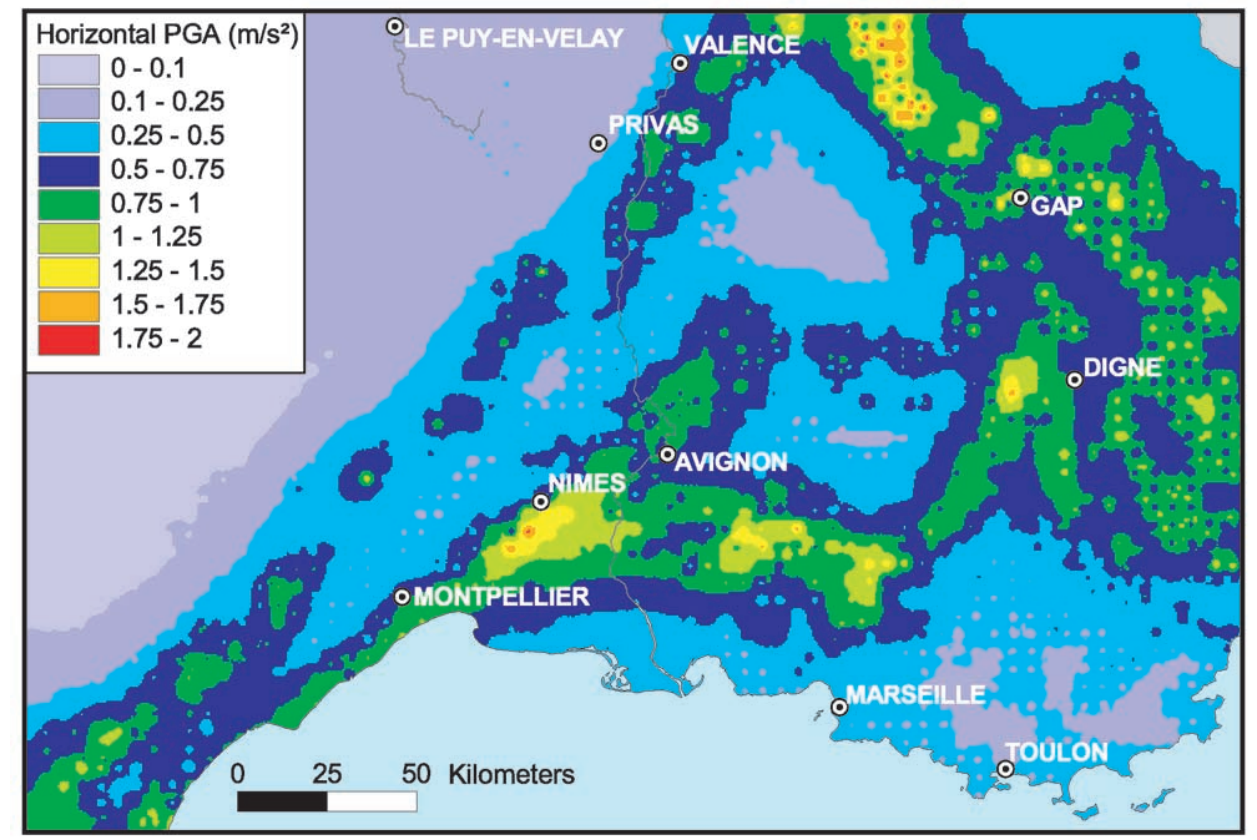

Figure 20. Effect of active faults on the expected PGA in Provence for a 1975-year return period.

have return periods of many hundred years to a few thousand years.) Variations are at most of a factor 15.4. The maximum acceleration values $\left(9.51 \mathrm{~m} / \mathrm{sec}^{2}\right)$ reached in the region of Vauvert-Alpilles, Costes-Trévaresse, and Durance can be explained by most unfavorable geological conditions.

\section{Disaggregation}

A disaggregation of seismic hazard at a site usually displays the relative contributions of events to the ground-motion exceedance probability in terms of ranges of magnitude and distances. Formally, the contribution of an earthquake of magnitude $m$ and distance $r$ to the expected acceleration level $a$ at a given site is:

$$
\rho(m, r)=\frac{I[\mathrm{PGA}>a / m, r] f_{\mathrm{M}}(m) f_{\mathrm{R}}(r)}{\lambda(a)}
$$

This representation of hazard can be improved by a disaggregation over latitude and longitude rather than distance (Bazzuro and Cornell, 1999; Harmsen et al., 1999; Harmsen and Frankel, 2001). Such geographic disaggregation enables the location on a map of all epicenters that contribute to the hazard and to point out the dominating magnitude for each with their joint contribution. A straight analysis of geographic disaggregation enables us to identify sources involved in the hazard, such as active faults, and to determine predominant earthquakes for a site. Predominant earthquakes are defined as the modal combinations (epicenter $x$ magnitude) of the joint contribution that is the most likely events.

Figure 22a shows the disaggregation of the hazard for
Table 6

Parameters of Active Faults in the Hypothesis of Paleoearthquakes

\begin{tabular}{lccc}
\hline Fault & $\begin{array}{c}\text { Local } \\
\text { Magnitude }\end{array}$ & $\begin{array}{c}\text { Return Period on } \\
\text { the Fault (years) }\end{array}$ & $\begin{array}{c}\text { Focal Depth } \\
(\mathrm{km})\end{array}$ \\
\hline Central Cévennes & 7.0 & 13,270 & 10 \\
Northern Cévennes & 7.0 & 13,270 & 10 \\
Southern Cévennes & 7.0 & 8,845 & 10 \\
Concors & 6.0 & 890 & 5 \\
Costes & 6.0 & 445 & 5 \\
Durance & 7.0 & 13,270 & 10 \\
Western Lubéron & 6.5 & 2,635 & 5 \\
Nîmes & 7.0 & 5,310 & 10 \\
Trévaresse & 6.0 & 980 & 5 \\
Vauvert-Alpilles & 6.5 & 880 & 5 \\
Ventoux-Lure & 7.0 & 13,270 & 10 \\
\hline
\end{tabular}

the quiet seismicity zone of the Paris Basin. The disaggregation has been performed at Paris city for a 1975-year return period. Maximum expected accelerations are of $0.09 \mathrm{~m} /$ $\sec ^{2}$ on quaternary sediments. The map shows that the hazard is dominated by the contribution of events located in the Paris Basin in a radius of $30 \mathrm{~km}$ round the city. Most likely, earthquakes of the diffuse seismicity zone are events of magnitude from 4.1 to 4.9 , which is the maximum observed magnitude of the zone. The earthquakes of magnitude 4.1 at 0 to $7 \mathrm{~km}$ from the city dominate the hazard with individual contributions of $1.4 \%$ and with a cumulated contribution on their own of $9.8 \%$ of the whole hazard at the city. The earthquakes of greatest magnitude 4.9 at 25 to 30 $\mathrm{km}$ from the city have individual contributions of $0.2 \%$ and a cumulated contribution of $10.4 \%$ of the whole hazard at 


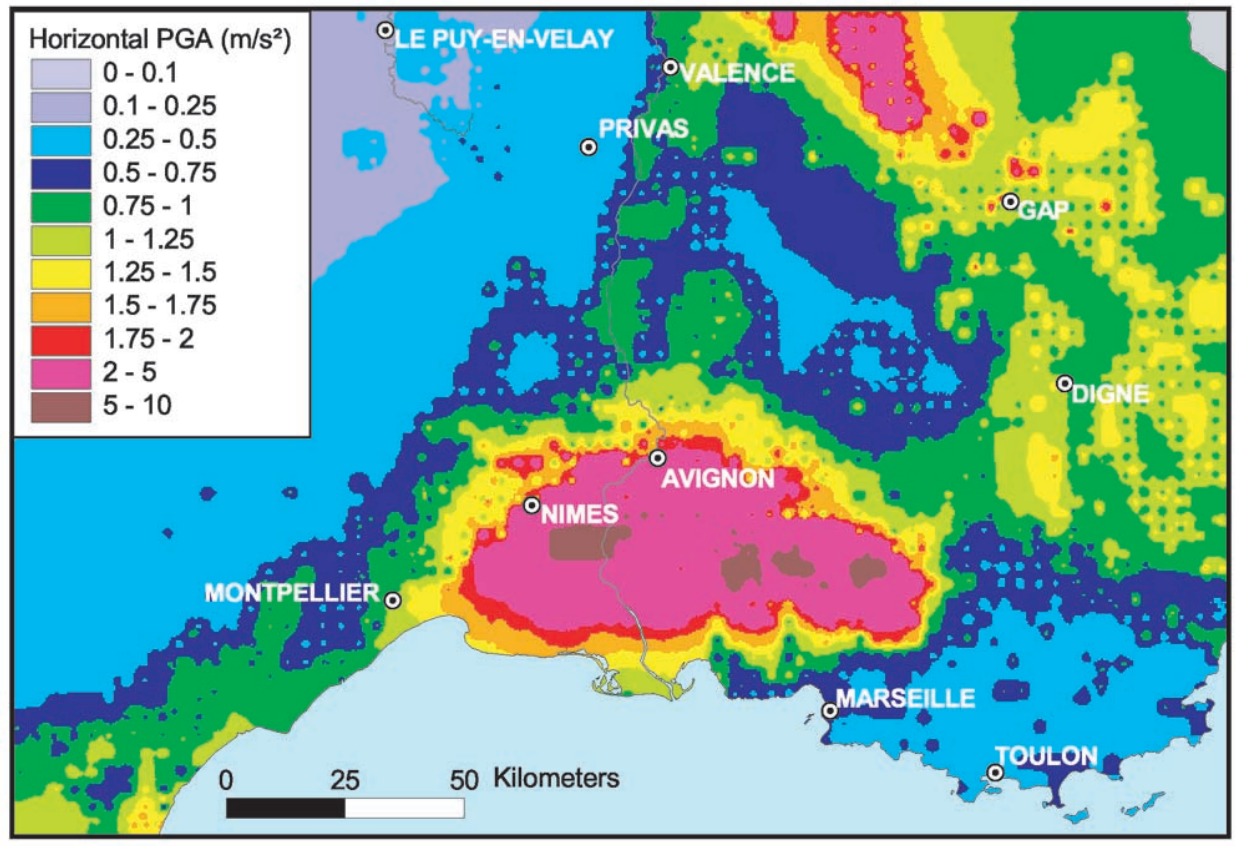

Figure 21. Effect of paleoearthquakes on the expected PGA in Provence for a 1975year return period.
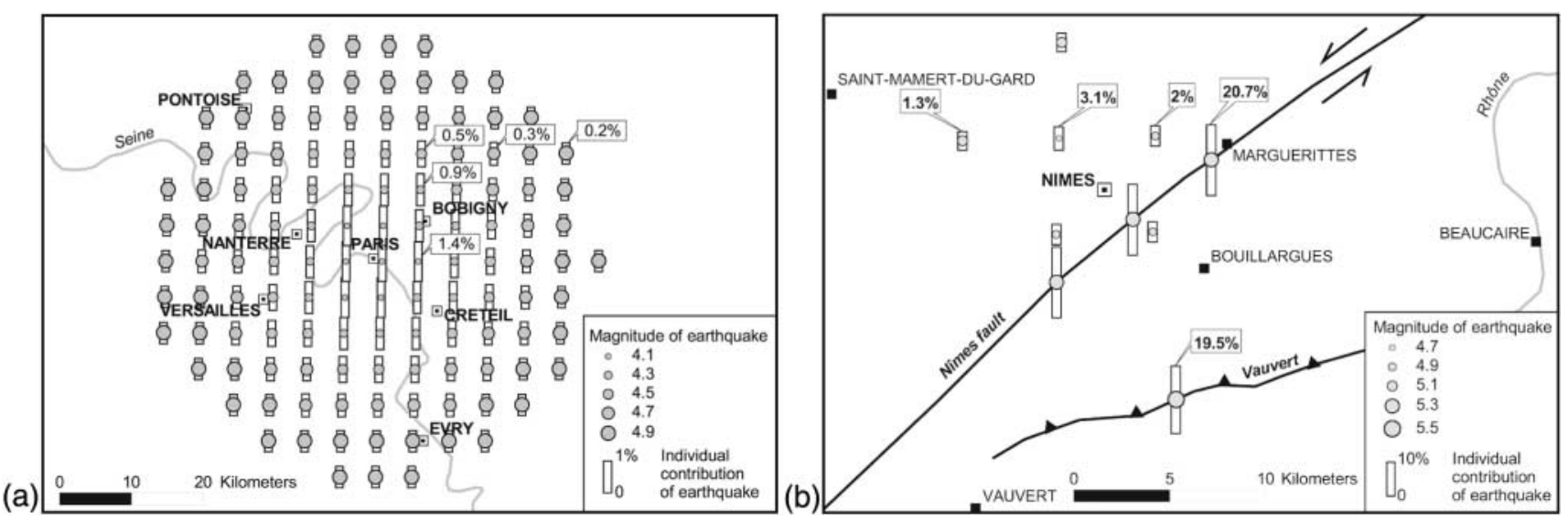

Figure 22. (a) Most likely earthquakes at Paris city for a 1975-year return period. The grey points are the epicenters of the simulated earthquakes that contributed to the hazard. They are evenly distributed every $5 \mathrm{~km}$. All magnitudes between 3.9 and the maximum of the zone (4.9) are simulated. The disaggregation map points out the dominating magnitude on each epicenter with their joint contribution to the hazard represented by the white bars. (b) Most likely earthquakes at Nîmes city for a 1975year return period. The grey points are the epicenters of the simulated earthquakes that contributed to the hazard. They are evenly distributed every $5 \mathrm{~km}$. On each epicenter associated with a fault, only the characteristic magnitude is simulated. On each epicenter associated with a zone, all magnitudes between 3.9 and the maximum of the zone (5.1) are simulated. The disaggregation map points out the dominating magnitude on each epicenter with their joint contribution to the hazard represented by the white bars.

the city. The cumulated contributions of most likely earthquakes of the diffuse zone account for $54.2 \%$ of the whole hazard at Paris city for a 1975-year return period.

Geographic disaggregation of the hazard in the region of Provence where active faults are included in the seismicity model is of interest. We performed the disaggregation for a 1975-year return period (Fig. 22b) at Nîmes city where maximum accelerations of about $1 \mathrm{~m} / \mathrm{sec}^{2}$ are expected on quaternary sediments. First, the map shows that hazard is dominated by events located in a near field in a radius of 12.5 


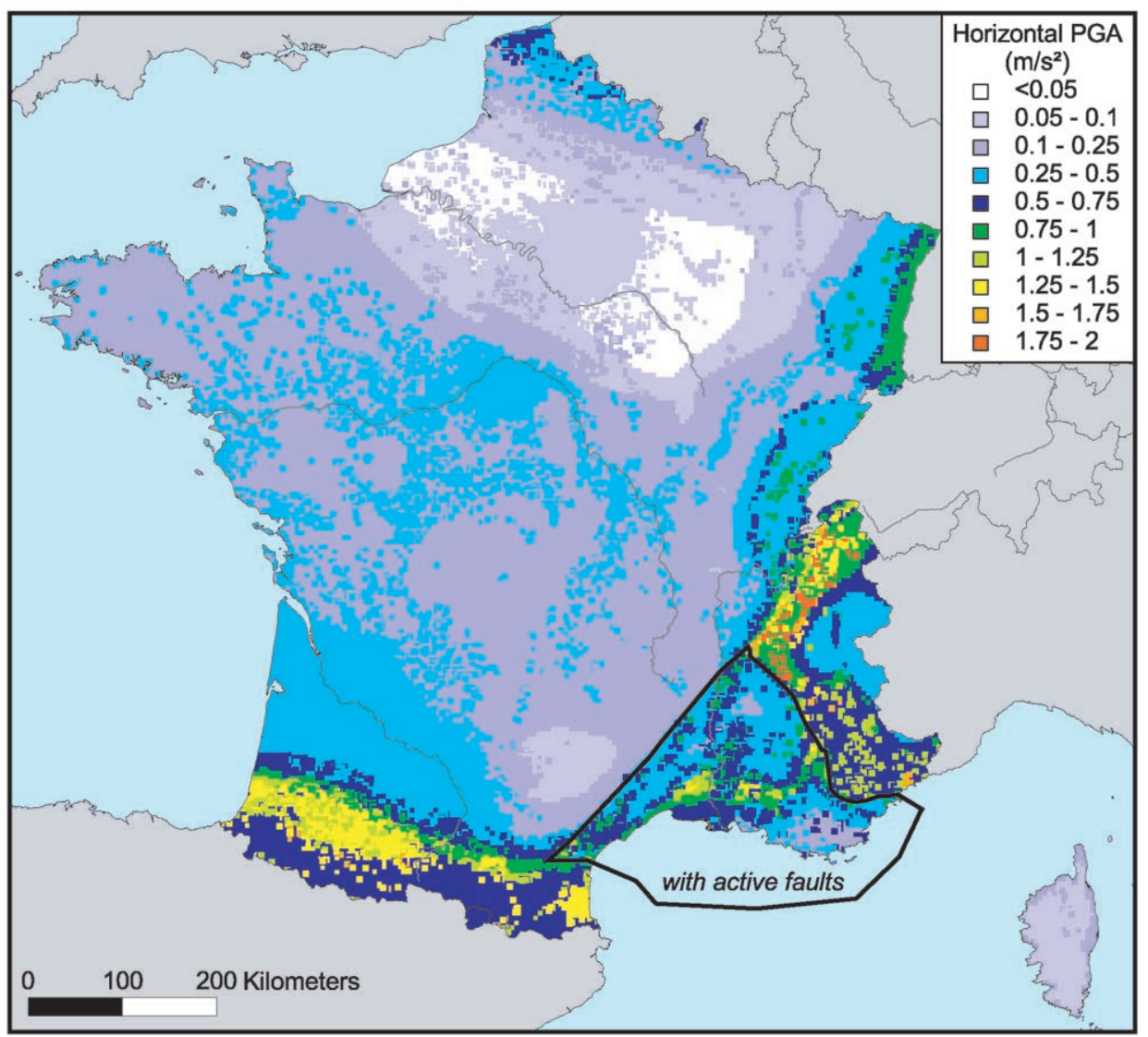

Figure 23. Effect of variability of ground motion on the expected PGA for a 1975year return period.

$\mathrm{km}$ round the city. It also confirms that the high acceleration values are due to the simultaneous contributions of the Nîmes and Vauvert faults. The most likely earthquakes are events of magnitude 5.3 on the Nîmes fault at 2.5 to $6 \mathrm{~km}$ from the city. These events dominate with individual contributions of $20.7 \%$ and with a cumulated contribution on their own of $62 \%$ of the whole hazard at the city. The earthquake of greatest magnitude 5.5 on the Vauvert fault located at $12.5 \mathrm{~km}$ from the city contributes $19.5 \%$ to the hazard. Most likely, earthquakes of the diffuse seismicity zone of Provence located in a radius of $4 \mathrm{~km}$ for magnitudes 4.7 and in a radius of $9 \mathrm{~km}$ for magnitudes 5.1, respectively, contribute for $3.1 \%$ and $1.3 \%$ to the hazard. The contribution of the diffuse seismicity zone is minor compared with the case of Paris with a cumulated contribution of only $11.5 \%$. The cumulated contributions of most likely earthquakes of these three sources account for $93 \%$ of the whole hazard at Nîmes city for a 1975-year return period.

\section{Sensitivity to Variability of Ground Motion}

In a second stage, we check the sensitivity of the results to the ground-motion model through two different comparisons: the first one concerns the variability inherent to the model and the second one the model in itself. The first com- parison consists in integrating the mean annual rate of occurrence on the variability of ground motion, and the second to use the attenuation law proposed by Ambraseys (1995) for Europe. The purpose is to study the importance of the uncertainty parameter compared with the choice of the model.

To assess the effect of the variability of ground motion on the hazard, the formulation of the mean annual frequency of exceedance of the acceleration level $a$ (equation 8) can be integrated over a Gaussian variable $\varepsilon$ defined as the logarithmic number of standard deviations by which the logarithmic predicted acceleration deviates from the mean:

$$
\begin{array}{r}
\lambda(a)=\sum_{\text {source }} v_{\text {source }} \times \iiint I[\mathrm{PGA} \geq a / m, r, \varepsilon] \\
f_{\mathrm{M}}(m) f_{\mathrm{R}}(r) f_{\varepsilon}(\varepsilon) d m d r d \varepsilon
\end{array}
$$

where $f_{\varepsilon}(\varepsilon)$ is the standardized Gaussian density function of variable $\varepsilon$.

In the computation we allowed a maximum deviation of one standard deviation $\sigma_{\log \text { PGA }}$ for the logarithmic predicted PGA (the probability density function is truncated to zero outside), with $\sigma_{\log P G A}=0.3$ : 


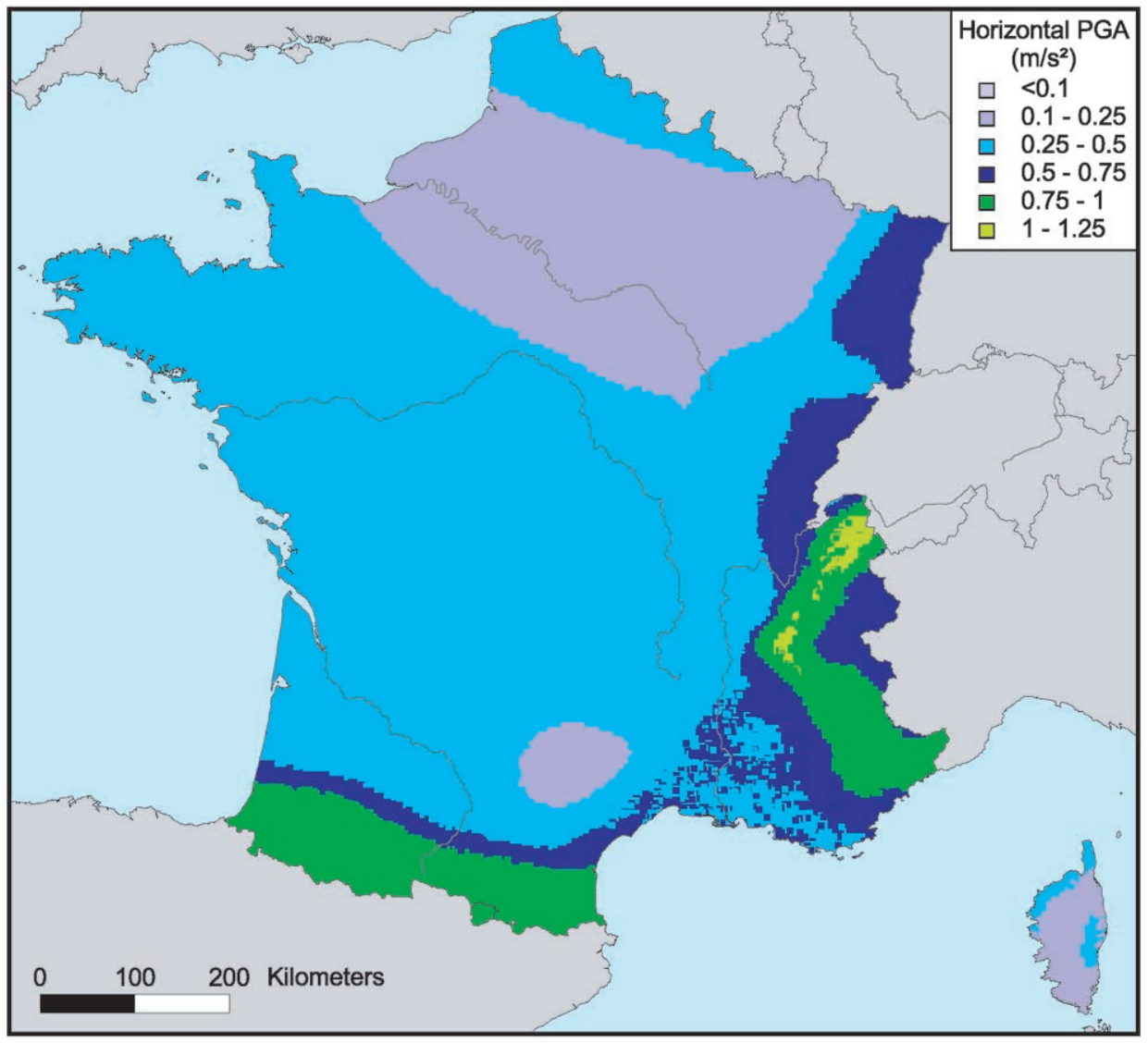

Figure 24. Expected PGA inferred from Ambraseys attenuation law (1995) for a 475-year return period.

$$
\begin{aligned}
\log _{10} \text { PGA }= & -3.93 \\
& +0.78 M_{\mathrm{L}}-1.5 \log _{10} R+\varepsilon \sigma_{\log \text { PGA }}
\end{aligned}
$$

Variability of ground motion has no significant effect on the hazard map for the 475-year return period that corresponds to a probability of exceedance of $10 \%$ in 50 years. Only the hazard map for the 1975-year return period performed with the integration (Fig. 23) displays significant effects compared with the map performed without the integration (Fig. 15). This map corresponds to a probability of exceedance of $2.5 \%$ in 50 years, that is, to the highest accelerations. Computation is performed with active faults taken into account in the seismicity model of the Provence. The map shows local increases of accelerations in the most seismic zones (the Alps and the Pyrenees) as well as in the less ones (the Aquitaine Basin, the Paris Basin, the ArtoisBrabant). A decrease of accelerations can also be noticed for the higher acceleration values due to faults. Variations are at most of a factor 1.4.

\section{Sensitivity to Attenuation Law}

A sensitivity study with regard to the choice of groundmotion model has been performed. For this purpose, we used the attenuation law proposed by Ambraseys for Europe
(1995). We mentioned before that local magnitude has to be converted to surface-wave magnitude. The corresponding hazard map is computed for a 475-year return period (Fig. 24), without geological conditions, because Ambraseys law already depends on various geological conditions. Without geological conditions in the evaluation of expected accelerations, the hazard map clearly delineates seismotectonic zonation boundaries. Values are globally higher than those obtained with the attenuation law established from French data (Fig. 13). This result was expected from the comparison of both attenuation laws (Fig. 3b). Variations are at most of a factor 8.2. The choice of the attenuation law is an order above the influence of ground-motion variability. Assessment of an attenuation law adapted to the French context, with respect to local magnitudes, clearly is of main importance in seismic hazard analysis.

\section{Conclusion}

This study illustrates how PSHA methodology can be applied to an area with moderate seismicity. In a recent study, Beauval et al. (2002) quantified the influence of the uncertainties inherent to the French seismicity catalogs (estimation of macroseismic magnitudes, determination of periods of completeness) in PSHA results. They obtained co- 
efficients of variation less than $20 \%$ and $15 \%$ for the seismic parameter estimates (the activity rate and the $b$-value, respectively). As for the final results of hazard assessment, the coefficient of variation of the PGA varies between 0 and $25 \%$. This low variability is certainly due to the Weichert method, which is essentially based on low magnitudes for which return periods are well constrained and reliable. Nevertheless, the present study points to the importance of testing internal consistency of the various data sets and laws to be used in any seismic hazard analysis. In particular, the type of magnitude used to characterize the seismotectonic model must be consistent with that used to predict ground motion. If not, some systematic bias is introduced that may result in systematic errors by a factor possibly up to 10 on PGA determination. We also show that the introduction of possible very large infrequent events, known only from paleoseismic investigations may have a dramatic impact on the hazard, especially when long periods of time and/or low level of probability of exceedance are considered. The outcome of the study can be expressed by maps showing the amplitude of ground acceleration that should be expected in France with some level of probability over certain periods. However the sensitivity tests and estimates of uncertainties should not be ignored because they provide some insight on the main source of uncertainty in such an analysis. In addition they provide guidelines to prioritize future research to focus on the major factors that contribute to the uncertainties. The determination of an attenuation law calibrated for local seismicity appears as a major goal. As far as long return periods are concerned, the detection of fault associated with the strongest known earthquakes or with localized active deformation also becomes a major goal. Also there is a need for some physical rationale, applicable in an area with little tectonic activity, to help define the seismotectonic model.

\section{Acknowledgments}

We wish to thank Jean-Paul Santoire who contributed to the elaboration of the attenuation law. We express our gratitude to Anne Replumaz for her collaboration to the research concerning the seismotectonic zonation. We also thank Alain Gachon and Bruno Hernandez for their helpful contributions to the discussion. We are grateful to Fabian Bonilla for his careful review of the manuscript, with many helpful suggestions and constructive discussions on the different subjects, which considerably improved the presentation of our approach. We also wish to thank an anonymous reviewer for his useful comments.

\section{References}

Albarello, D., A. Berardi, C. Margottini, and M. Mucciarelli (1995). Macroseismic estimates of magnitude in Italy, Pure Appl. Geophys. 145, 297-312.

Ambraseys, N. N. (1974). The correlation of intensity with ground motions, in Proc. of the 14th Conference of the European Seismological Commission, Trieste, Italy, 16-22 September 1974.

Ambraseys, N. N. (1985). Intensity-attenuation and magnitude-intensity relationships for western European earthquakes, Earthquake Eng. Struct. Dyn. 13, 733-778.
Ambraseys, N. N. (1995). The prediction of earthquake peak ground acceleration in Europe, Earthquake Eng. Struct. Dyn. 24, 467-490.

Association Française du Génie Parasismique (1990). Recommandations AFPS 90 pour la rédaction de règles relatives aux ouvrages et installations à réaliser dans les régions sujettes aux séismes, Presses de l'Ecole Nationale des Ponts et Chaussées, Paris, France.

Atkinson, G. M., and E. Sonley (2000). Empirical relationships between Modified Mercalli Intensity and response spectra, Bull. Seism. Soc. Am. 90, 537-544.

Bard, P. Y., J. L. Durville, J. P. Meneroux, and P. Mouroux (1992). The French experience in seismic zonation, in Recent advances in Earthquake Engineering and Structural Dynamics, Ouest éditions, Presses Académiques, Nantes, France, 65-88.

Baroux, E. (2000). Tectonique active en région à sismicité modérée: le cas de la Provence (France). Apport d'une approche pluridisciplinaire, Ph.D. Thesis, University of Paris XI Orsay, France.

Baroux, E., N. A. Pino, G. Valensise, O. Scotti, and M. E. Cushing (2003). Source parameters of the 11 June 1909, Lambesc (Provence, southern France) earthquake: a reappraisal based on macroseismic, seismological, and geodetic observations, J. Geophys. Res. 108, no.B9, ESE 16, $1-23$.

Bazzurro, P., and C. A. Cornell (1999). Disaggregation of seismic hazard, Bull. Seism. Soc. Am. 89, 501-520.

Beauval, C., D. Bertil, F. Bonilla, and O. Scotti (2002). Impact of data uncertainties on French PSHA results using synthetic catalogues, in Proc. of the 27th General Assembly of the European Geophysical Society, Nice, France, 21-26 April 2002.

Boatwright, J., K. Thywissen, and L. C. Seekins (2001). Correlation of ground motion and intensity for the 17 January 1994 Northridge, California, earthquake, Bull. Seism. Soc. Am. 91, 739-752.

Boore, D. M., and B. Joyner (1997). Site amplifications for generic rock sites, Bull. Seism. Soc. Am. 87, 327-341.

Bossu, R., O. Scotti, F. Cotton, M. Cushing, and A. Levret (2000). Determination of geomechanical site effects in France from macroseismic intensities and reliability of macroseismic magnitude of historical events, Tectonophysics 324, 81-110.

Bour, M., P Dominique, J. L. Blès, P. Godefroy, C. Martin, and M. Terrier (2000). Zonation of metropolitan France for the application of earthquake-resistant building regulations to critical facilities, Part 2: Seismotectonic zonation, J. Seism. 4, 231-245.

Bureau de Recherques Géologiques (1996). Carte géologique de la France à l'échelle du millionième, Sixth Ed., Bureau de Recherches Géologiques et Minières, Orléans, France.

Campbell, K. W. (1997). Empirical near-source attenuation relationships for horizontal and vertical components of peak ground acceleration, peak ground velocity, and pseudo-absolute acceleration response spectra, Seism. Res. Lett. 68, 154-179.

Cara, M., D. Rouland, E. Peterschmitt, and L. Trotignon (1987). Historical instruments and seismograms in Strasbourg, Gerlands Beitr. Geophys. 96, 374-384.

Combes, P., D. Carbon, M. Cushing, T. Granier, and P. Vaskou (1993). Mise en évidence d'un paléoséisme pléistocène supérieur dans la vallée du Rhône: implications sur les connaissances de la sismicité de la France, C. R. Acad. Sci. Sér II 317, 689-696.

Cornell, C. A. (1968). Engineering seismic risk analysis, Bull. Seism. Soc. Am. 58, 1583-1606.

D'Amico, V., and D. Albarello (1999). The problem of regionalization in the study of magnitude-intensity correspondences in the Mediterranean area: a distribution-free approach, Pure Appl. Geophys. 156, $651-665$.

Di Maro, R., and A. Tertulliani (1990). The relation between intensity and magnitude for Italian earthquakes, Pure Appl. Geophys. 132, 711718.

EPAS Working Group Autran, A., J. L. Blès, P. Combes, M. Cushing, P. Dominique, C. Durouchoux, J. C. Gariel, X. Goula, B. Mohammadioun, and M. Terrier (1998a). Probabilistic seismic hazard assessment in France, Part I: Seismotectonic zonation, in Proc. of the 11th 
European Conference on Earthquake Engineering, Paris, France, 611 September 1998.

EPAS Working Group Dominique, P., A. Autran, J. L. Blès, D. Fitzenz, F. Samarcq, M. Terrier, M. Cushing, J. C. Gariel, B. Mohammadioun, P. Combes, C. Durouchoux, and X. Goula (1998b). Part two: Probabilistic approach: seismic hazard map on the national territory (France), in Proc. of the 11th European Conference on Earthquake Engineering, Paris, France, 6-11 September 1998.

Grellet, B., P. Combes, T. Granier, and H. Philip (1993). Sismotectonique de la France métropolitaine dans son cadre géologique et géophysique avec atlas de 23 cartes au 1/4000000 et une carte au 1/1000000, Mem. Soc. Geol. Fr. 164.

Gutenberg, B., and C. F. Richter (1956). Earthquake magnitude, intensity, energy and acceleration, Bull. Seism. Soc. Am. 46, 105-145.

Harmsen, S. C. (1997). Determination of site amplification in the Los Angeles urban area from inversion of strong-motion records, Bull. Seism. Soc. Am. 87, 866-887.

Harmsen, S., and A. Frankel (2001). Geographic deaggregation of seismic hazard in the United States, Bull. Seism. Soc. Am. 91, 13-26.

Harmsen, S., D. Perkins, and A. Frankel (1999). Deaggregation of probabilistic ground motions in the central and eastern United States, Bull. Seism. Soc. Am. 89, 1-13.

Laboratoire de Détection et de Géophysique (LDG) (1998). Catalogue of French seismicity 1962-1998, CEA/Laboratoire de Détection et de Géophysique, Bruyères-le-Châtel, France.

Lacassin, R., B. Meyer, L. Benedetti, R. Armijo, and P. Tapponnier (1998). Signature morphologique de l'activité de la faille des Cévennes (Languedoc, France), C. R. Acad. Sci. Ser. II 326, 807-815.

Levret, A., J. C. Backe, and M. Cushing (1994). Atlas of macroseismic maps of French earthquakes with their principal characteristics, Nat. Hazards 10, 19-46.

Levret, A., M. Cushing, and G. Peyridieu (1996). Recherche des Caractéristiques de Séismes Historiques en France, Atlas de 140 Cartes Macrosismiques, Publications de l'IPSN, Fontenay-aux-Roses, France.

Massinon, B., and J. Vogt (1985). Sismicité historique et sismicité instrumentale, in Génie Parasismique, V. Davidovici (Editor), Presses de l'Ecole Nationale des Ponts et Chaussées, Paris, France, 179-186.

Murphy, J. R., and L. J. O'Brien (1977). The correlation of peak ground acceleration amplitude with seismic intensity and other physical parameters, Bull. Seism. Soc. Am. 67, 877-915.

Nicolas, M., N. Bethoux, and B. Madeddu (1998). Instrumental seismicity of the Western Alps: a revised catalogue, Pure Appl. Geophys. 152, 707-731.

Park, S., and S. Elrick (1988). Prediction of shear wave velocities in southern California using surface geology, Bull. Seism. Soc. Am. 88, 677685.

Peterson, M., W. Bryant, C. Cramer, M. Reichle, and C. Real (1997). Seismic ground motion hazard mapping incorporating site effects for Los Angeles, Orange, and Ventura counties, California: a geographical information system application, Bull. Seism. Soc. Am. 87, 249-255.

Schlupp, A., G. Clauzon, and J. P. Avouac (2001). Mouvement postmessinien sur la faille de Nîmes: implications pour la sismotectonique de la Provence, Bull. Soc. Geol. Fr. 172, 697-711.

Schwartz, D. P., and K. J. Coppersmith (1984). Fault behavior and characteristic earthquakes: examples from the Wasatch and San Andreas fault zones, J. Geophys. Res. 89, 5681-5698.

Scotti, O., A. Levret, and B. Hernandez (1999). Verification of macroseismic methods on five ML $>5$ instrumental earthquakes in France, Phys. Chem. Earth A 24, 495-499.

SIRENE (1996). Base de la Macrosismicité Française, Commissariat à l'Energie Atomique/Institut de Protection et de Sûreté NucléaireBureau de Recherches Géologiques et Minieres-Electricité de France.

Smit, P. M. (1998). Strong motion attenuation model for central Europe, in Proc. of the 11th European Conference on Earthquake Engineering, Paris, France, 6-11 September 1998.
Steidl, J. H. (2000). Site response in Southern California for probabilistic seismic hazard analysis, Bull. Seism. Soc. Am. 90, no. 6B, S149-S169.

Terrier, M., J. L. Blès, P. Godefroy, P. Dominique, M. Bour, and C. Martin (2000). Zonation of metropolitan France for the application of earthquake-resistant building regulations to critical facilities. Part 1: Seismic zonation, J. Seism. 4, 215-230.

Theodulidis, N. P., and B. C. Papazachos (1992). Dependence of strong motion on magnitude- distance, site geology and macroseismic intensity for shallow earthquakes in Greece. I: peak horizontal acceleration, velocity and displacement, Soil Dyn. Earthquake Eng. 11, 387-402.

Tinti, S., T. Vittori, and F. Mulargia (1986). Regional intensity-magnitude relationships for the Italian territory, Tectonophysics 127, 129-154.

Wald, L. A., and J. Mori (2000). Evaluation of methods for estimating linear site-response amplifications in the Los Angeles basin, Bull. Seism. Soc. Am. 90, no. 6B, S32-S42.

Wald, D. J., V. Quitoriano, T. H. Heaton, and H. Kanamori (1999a). Relationships between peak ground acceleration, peak ground velocity, and Modified Mercalli Intensity in California, Earthquake Spectra 15, $557-564$.

Wald, D. J., V. Quitoriano, T. H. Heaton, H. Kanamori, C. W. Scrivner, and C. B. Worden (1999b). Trinet "ShakeMaps": rapid generation of peak ground motion and intensity maps for earthquakes in southern California, Earthquake Spectra 15, 537-555.

Weichert, D. H. (1980). Estimation of the earthquake recurrence parameters for unequal observation periods for different magnitudes, Bull. Seism. Soc. Am. 70, 1337-1346.

Wells, D. L., and K. J. Coppersmith (1994). New empirical relationships among magnitude, rupture length, rupture width, rupture area and surface displacement, Bull. Seism. Soc. Am. 84, 974-1002.

Wills, C. J., M. Petersen, W. A. Bryant, M. Reichle, G. J. Saucedo, S. Tan, G. Taylor, and J. Treiman (2000). A site-conditions map for California based on geology and shear-wave velocity, Bull. Seism. Soc. Am. 90, no. 6B, S187-S208.

Yeats, R. S., K. E. Sieh, and C. R. Allen (1997). The Geology of Earthquakes, Oxford University Press, New York.

\section{Appendix}

The local magnitude $M_{\mathrm{L}}(\mathrm{LDG})$ is calculated from records obtained by the LDG network and based on the maximum amplitude of the $S / L g$-waves on the vertical component. For each record,

$$
M_{\mathrm{L}}(\mathrm{LDG})=\log A / T+B(\Delta)+C
$$

where $A$ is the maximum amplitude of the $S / L g$ wave, $T$ is the corresponding period, $B(\Delta)$ is the corrective regional parameter of attenuation at the distance $\Delta$, and $C$ is the station coefficient. The $C$ coefficient is used to match the $M_{\mathrm{L}}$ with an international reference, which is the $m b$ of ISC for the $M_{L}$ of LDG (Massinon and Vogt, 1985). The $M_{\mathrm{L}}(\mathrm{LDG})$ is finally obtained as the mean of all individual magnitudes calculated with this method. The LDG network is composed of about 40 stations since 1994. As the calculation of the local magnitude remains the same since the beginning of the instrumental period in 1962, the national catalog is complete and homogeneous.

Laboratoire de Détection et de Géophysique CEA/DAM Île de France

BP 12, 91680 Bruyères-le-Châtel, France

Manuscript received 30 October 2003. 